\title{
Metals: Resources or Financial Assets? A Multivariate Cross-Sectional Analysis
}

\author{
Fabian Lutzenberger ${ }^{(\mathrm{b})}$, Benedikt Gleich ${ }^{(\mathrm{a})}$, Herbert G. Mayer ${ }^{(\mathrm{a})}$, \\ Christian Stepanek ${ }^{(a)}$, Andreas W. Rathgeber ${ }^{(a)}$
}

\footnotetext{
(a) Professorship for Finance, Information \& Resource Management, Institute of Materials Resource Management, University of Augsburg, 86135 Augsburg, Germany, Correspondence author: andreas.rathgeber@mrm.uni-augsburg.de, Tel.: +49 821 $598-3040$
}

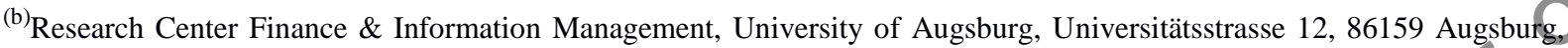
Germany

\section{Abstract}

Metals are very important resources for industrial production, but recently they have attracted more and more attention from investors. While certainly industriapproducers, consumers, and financial investors do have some influence on metal price development, the role of releyant price factors is not yet quite clear. Therefore, in this paper we examine the explanatory power of various fundamental factors and characteristics known from financial markets, specifically on the expected returns in unique data sample of 30 metals.

We apply - to our knowledge for the first time in this context - the widely accepted method of characteristicsorted portfolios, extended by the very recent method of two-way portfolio sorts as an alternative to classical multivariate regressions. This mostly non-parametric approach, combined with portfolio aggregation, provides very robust results. Our major finding is that the financial characteristics value and momentum have a very high predictive power formonthly returns of metal portfolios. Metal-specific fundamental factors like stocks, secondary production, apparent consumption, country concentration, mine production, or reserves perform depending on the interpretation moderately well or rather poorly, regarding some economically interpretable transformations and when using multivariate two-way sorts. Hence, from the perspective of expected returns, metals are predominantly assets, while fundamental metal-specific factors still play a non-negligible role. Thus, to a much lesser extent, metals can still be regarded as resources. Overall, the combination of financial characteristics and metal-specific fundamental factors yields the best results. With these robust results, we hope to contribute to a better understanding of metal prices and their underlying factors.

\section{Keywords}

Metals, value, momentum, fundamentals, cross-sectional analysis, non-parametric.

\section{JEL-Classification}

G12, G17, Q02 


\section{Introduction}

Commodities and metals in particular, have always been crucial resources for many primary industries and are still indispensable to the modern economy. Besides their fundamental industrial importance, metals as financial assets have played an increasingly important role in financial markets in the last decade.

Following the above two perspectives on commodities, this paper takes into consideration two models of metal prices: an economic explanation and a financial one (see among others Borensztein and Reinhart, 1994). The former interprets the prices of resources as a function of microeconomic, commodity-specific factors, such as supply and demand. The latter builds on the early work of Frankel (1986). According to his idea, commodities behave in the short term like financial assets, and are therefore dependent on interest rates and other monetary aggregates. Correspondingly, this view derives from the idea in financial literature that commodities obey the same rules as financial assets, and, although this concept has been developed independently from economic literature, it is the dominating view in financial literature. The goal of our analysis is to contrast the two perspectives and determine which is more pronounced. To this end, we examine the explanatory power of various fundamental factors related to the supply and demand of metals, as well as characteristics known from financial markets, on average monthly returns in a cross-section analysis.

In order to present the specific contribution of our approach, we analyze the different strands in relevant literature. From the theoretical economic perspective, prices of commodities are determined by supply and demand factors. To be more specific, the fundamental economic factors analyzed are on the one hand macroeconomic factors and on the other hand microeconomic factors that apply specifically to just one metal. Starting with microeconomic determinants the overwhelming majority of studies (see e.g. Baffes and Savescu 2014, Chai et al. 2011, Nick and Thoenes 2014) find a negative relationship between stocks as supply factor, in theory negatively related to prices, and prices. Other studies observe a convincingly significant positive influence of the OPEC cartel as a proxy for market concentration on oil prices whereas reserves (e.g. see) or the amount of recycling play a minor role (see e.g. Gleich et al. 2013, Merion and Ortiz 2005). Regarding the demand perspective some studies focus on the demand of special countries, like China and South Korea, and are thus able to show their significant positive influence on prices (see e.g. Klotz et al. 2014). However, most studies use the macroeconomic factor global economic activity as proxy for demand (see e.g, Kilian 2009, Poncela et al. 2014) and show a significant influence of the world industrial production etc. on real and nominal prices. Here, different resource prices have different elasticities, with respect to changes in the economic activity (see Belke et al. 2014). Among the monetary macroeconomic factors inflation drives the prices of nominal as well as real commodities prices (see e.g. Belke et 
al. 2010) with different extents of overshooting for different commodities. Regarding further monetary variables, many studies show a significant long-term equilibrium relationship between the dollar rate and commodity prices, as well as between interest rates and commodity prices, especially regarding oil and indices (see e.g. Arango et al. 2012, Chen et al. 2016). The direction of the Granger causality is open, and, consequently, results in a lead-lag relationship (see e.g. Lastrapes and Selgin 2001).

We now turn to the purely financial strand of literature, which is deeply rooted in the theory of capital markets. According to this theory (e.g. see Sharpe 1964), expected returns of all assets are driven by their volatility and correlation to the market portfolio, whereby other factors like interest rates or economic activity, in the form of state variables, can additionally influence the expected returns in a dynamic model setting (Merton 1973). Following this idea, empirical examinations of commodity future returns are mainly concerned with the crosssectional investigation of risk premium of commodity futures. In an early analysis, Dusak (1973) finds no evidence for systematic risk, despite the fact that the return variability of the examined futures is comparable to that of stock indexes. Breeden (1980) describes the risk premium with a consumption CAPM, and finds that it plays a significant role in some commodity futures' prices. According to Asness et al. (2013), commodity futures below their long-term mean price have higher returns in the future, which is called a value effect in the literature of financial economics. Furthermore, in a time series setting, Hong and Yogo (2012) and Lutzenberger (2014) show that commodity future returns are predictable via various variables from the stock market, bond market, macroeconomics, and the commodity market. Nevertheless, future returns deviate substantially from spot returns. Consequently, risk premiums in future returns can be disentangled into a term premium, which is earned by holding futures, and a spot premium by holding the resource. In a very recent study by Szymanowska et al. (2014), which comes closest to our line of reasoning, the authors explicitly differentiate between both premiums. However, they analyze no fundamental factors, but only observe financial characteristics as determinants of spot price returns.

Overall, most of the studies concentrate either on fundamental economic (partly monetary) variables or on financial variables. The economic studies using (individual) time series of spot prices of a few commodities or commodity indices leading to mixed results with regard to the dependencies and are more pronounced with regard to the lead lag relationship. The financial studies analyze the relationship between factors known from asset pricing (partly macroeconomic variables) leading to results, in which factors known from other asset returns have forecasting power on commodity returns. In this line, we apply the cross-section methodology to ascertain if factors known from asset pricing may predict future commodity and in particular metal spot returns better than factors known from the economic literature, or vice versa. In particular, we focus on metal-specific microeconomic factors as 
well as on elasticities of macroeconomic factors, and analyze influence on the expected or cross-section average monthly spot returns of metals over the period of 24 years, from January, 1990 to December, 2013. Therefore, we sort metals into portfolios according to a particular characteristic, and examine whether the average returns of these characteristic-sorted portfolios differ significantly from each other. At this juncture, we apply a new test method for two-way sorted portfolios according to Patton and Timmermann (2010), in order to account for possible dependencies in the explaining factors, focusing especially on combinations of factors known from economic and financial literature.

We contribute to the economic literature by applying an alternative method, the cross-sectional empirical examination, to find out the determinants of commodity prices, including typical financial factors. Our contribution to the financial literature is to include typical commodity-specific microeconomic factors - using a unique data sample of 30 metals - in the analysis of spot prices.

The remainder of this paper is structured as follows: Section 2 introduces the portfolio formation methodology, corresponding variables, transformations, as well as our data sample. Section 3 describes the results of the empirical analysis. Section 4 gives an overview of our robustness checks. In section 5 we analyze the results in the light of existing approaches determining commodity prices and influencing factors. Section 6 concludes the paper.

\section{Empirical methodology and data}

General assumptions, our extensive data sample and our methodological framework to determine driving factors of metal prices or metal returns, respectively, are presented below.

\subsection{Portfolio formation}

Empirical asset pricing differentiates between two general views or approaches regarding the analysis of returns. On the one hand, there are studies that examine returns in time series. These papers assess whether future spot returns of metals are predictable by, e.g. asset-specific characteristics or cross-asset (macro) factors. For this purpose, future returns are usually regressed on the current values of one or more of these factors. On the other hand, there are researchers who focus on the cross-section of average returns. These studies seek to explain why some financial assets exhibit higher average returns than others. Hence, they assess which asset-specific characteristics cause a variation in average returns and can generally be interpreted as a nonparametric crosssectional regression of average returns on characteristics that use non-overlapping histogram weights (Cochrane 2011). In contrast to the first time series approach, these studies consider more than one asset (or more than one portfolio of assets) at once. There are several reasons why the analysis of portfolios is preferable to individual 
asset analysis, and hence is preferable in the context of metals. First, individual assets show a high variance of returns, resulting in "noisy" estimates of average returns (high standard errors). Consequently, the hypothesis that all assets have the same average returns can hardly be rejected for individual assets. The formation of portfolios lowers the variance of returns and makes the detection of significantly different average returns more likely. Second, characteristics measured in a first step, such as (for metals) the concentration of producing countries or producing companies, may vary over time, and are therefore also difficult to measure for individual assets. Third, forming portfolios of assets is what investors actually do from a financial perspective, so that practice and research are closer when portfolios are used in such tests (Cochrane 2005, chapter 20). Following Fama and French (1992), our paper takes the second point of view on the cross-section of metals, and obtains new insights via a different methodology.

To evaluate which (fundamental or financial) metal-specific characteristics are able to explain the cross-sectional variation of average returns of a number of metals, we first compute the log spot return, $r$, of each metal over a given month as the natural logarithm of the ratio of its spot price at the end of the month to its spot price at the beginning of the month. In the next step, we sort metals into portfolios based on the respective characteristic, and test for a significant spread in these portfolios' average returns. Specifically, we apply two different standard approaches for portfolio formation: high-minus-low portfolios and rank-weighted portfolios. The resulting portfolios are zero-cost long-short portfolios, i.e., an investor theoretically can hold these portfolios - on balance - without an initial investment or payment. We thereby employ three different frequencies for portfolio formation: monthly, yearly, and once. The monthly sorts are used for characteristics with monthly data frequency, the yearly sorts are employed for characteristics only available in a yearly frequency, and the one-time sorts are used for characteristics that do not change over time. We emphasize, however, that these portfolios are not meant to represent an implementable strategy for investors in practice, since the shorting of most of the metals we consider is - unlike shorting stocks - strongly limited. Apart from futures or novel commodity-linked (short) products, both subject to additional costs, shorting in spot markets is only possible in a very short-run (standard delivery obligation within 10 days) or for individual exceptions like gold. In addition, the trading of metals in general is associated with higher transaction costs as the trading of stocks.

Following Asness et al. (2013), high-minus-low portfolios for monthly characteristics are constructed as follows. Each month, metals are ranked by a characteristic $C$, and sorted into three equally large groups. In this sorting procedure, we only consider those metals having a value for the characteristic at the time of the portfolio composition, as well as a return in the following month (i.e. a price in the current and following month). Out of 
these three groups, we form three portfolios (low, middle, and high), in which all metals are equally weighted. We then calculate the monthly returns of each portfolio in the month serving as a basis for portfolio composition, and subtract the one-month U.S. Treasury bill rate from these returns. Finally, for each month we compute the spread in monthly returns between the third and first portfolios, $r_{t+1}^{C, \text { high }}$ and $r_{t+1}^{C, l o w}$, resulting in the monthly returns of the high-minus-low (HML) portfolio:

$$
r_{t+1}^{C, H M L}=r_{t+1}^{C, h i g h}-r_{t+1}^{C, l o w}
$$

We then test whether the average returns of the high-minus-low portfolio are significantly different from zero by computing the respective t-statistic. We repeat this procedure with each characteristic that changes monthly.

In addition to the high-minus-low portfolios, we form rank-weighted portfolios, again following Asness et al. (2013). These portfolios are zero-cost long-short portfolios that use - in contrast to the high-minus-low portfolios, which only consist of metals sorted into the first and third portfolios - the entire cross-section of metals. Returns on the factor of the rank-weighted portfolios for monthly characteristics are computed as follows. First, in each month $t$, each metal $i$ (having a value for the characteristic in the respective month as well as a return in the following month) is weighted in proportion to its cross-sectional rank based on the value of its characteristic in month $t$ (referred to as "signal" by Asness et al. 2013), $C_{i, t}$, minus the cross-sectional average rank of the characteristic. In particular, the weight of metal $i$ in month $t$, based on characteristic $C$, is computed as

$$
w_{i, t}^{C}=s_{t}\left(\operatorname{rank}\left(C_{i, t}\right)-\sum_{i=1}^{N} \operatorname{rank}\left(C_{i, t}\right) / N\right)
$$

where $N$ is the number of metals considered in the portfolio formation, and $s_{t}$ is a scaling factor that scales the portfolio to one dollar long and one dollar short. Thus, the sum of weights across all metals equals zero and the portfolio is dollar-neutral long-short. Second, in each month that follows the portfolio formation, $t+1$, the portfolio return is computed by summing the products of each metal's return in $t+1, r_{i, t+1}$, and its weight in $t$ :

$$
r_{t+1}^{C, R a n k}=\sum_{i=1}^{N} w_{i, t}^{C} r_{i, t+1}
$$

The test procedure then is identical to the one for the high-minus-low portfolios, described before. We repeat this procedure for each monthly-changing characteristic. 
The high-minus-low as well as the rank-weighted portfolios for yearly characteristics are built similarly to the portfolios based on monthly characteristics, except that the yearly portfolios are built in each year $t$ at the end of December using the value of the characteristic in $t$. Then, monthly returns are computed from January to December in year $t+1$ for these portfolios, formed at the end of December in $t$. The high-minus-low as well as the rankweighted portfolios for constant characteristics are built correspondingly to the monthly and yearly sorts, except that these portfolios are built only once.

\subsection{Multivariate portfolio formation}

We further face the problem that our methodology evaluates each characteristics in isolation, while the crosssection analysis aims to evaluate the importance of the financial characteristic while controlling for the effect of the fundamental characteristic and vice versa. In other words, we want to answer the question whether a pricing model with only fundamental characteristics can be improved by including value or momentum as additional characteristics.

Therefore, it is common practice in finance literature to use Fama and MacBeth (1973) type regressions to examine whether the characteristics can explain the cross-sectional variation of metal prices. Although we use a very large data set of 30 metals, a cross-sectional portfolio analysis using regressions (usually Fama MacBeth type) would hardly generate any significant results provided the low degrees of freedom given the number of portfolios in a cross-section analysis of 30 metals. Our methodology following Patton and Timmermann (2010) requires us to split up metals in $2^{n}$ portfolios (with $\mathrm{n}$ being the number of dimensions, e.g. independent variables), because for every possible combination (variable one high or low, variable two high or low and so on) we need one specific portfolio. Thus, the number of observations needed for additional explaining variables rises exponentially. For instance, for two explaining variables, we need four portfolios (leading to about seven metals per portfolio). However, three explaining variables already would require eight portfolios, reducing the metals per portfolio to only about four. For multivariate regressions, with about four or seven metals per portfolio, the number of observations (four or eight portfolios) is simply too low to allow any significant results.

Thus, due to the fact that there are not enough metals, we are unable to construct portfolios to which the time series and the cross-sectional regression could be applied. Consequently, this implies that we could only run the Fama and MacBeth type regressions on single metals, which suggests high standard errors in the metals average returns - thus leading to insignificant results. 
Hence, we choose an alternative methodology, following Patton and Timmermann (2010), by forming two-way sorted portfolios and applying a specialized test for the conditional differences in returns. Particularly, we sort the portfolios for two characteristics, $C_{1}$ and $C_{2}$, and therefore calculate the average of the returns for the four different portfolios $\bar{r}\left(r_{t+1}^{C 1, h i g h ; C 2, \text { high }}\right), \bar{r}\left(r_{t+1}^{C 1, l o w ; C 2, h i g h}\right), \bar{r}\left(r_{t+1}^{C 1, h i g h ; C 2, l o w}\right)$, and $\bar{r}\left(r_{t+1}^{C 1, l o w ; C 2, l o w}\right)$. According to Patton and Timmermann (2010) an appropriate test statistic for the joint event of a characteristic's $C_{1}$ predictability given a second characteristic $C_{2}$ is

$$
J\left(C_{1}\right)\left\{\begin{array}{l}
\max \left(\Delta \bar{r}^{C 1, H M L ; C 2, \text { high }}, \Delta \bar{r}^{C 1, H M L ; C 2, \text { low }}\right) \text { if } \Delta \bar{r}^{C 1, H M L ; C 2, \text { high }}<0 \text { and } \Delta \bar{r}^{C 1, H M L ; C 2, \text { low }}<0 \\
\min \left(\Delta \bar{r}^{C 1, H M L ; C 2, \text { high }}, \Delta \bar{r}^{C 1, H M L ; C 2, \text { low }}\right) \text { if } \Delta \bar{r}^{C 1, H M L ; C 2, \text { high }}>0 \text { and } \Delta \bar{r}^{C 1, H M L ; C 2, \text { low }}>0
\end{array}\right.
$$

whereby

$$
\begin{gathered}
\Delta \bar{r}^{C 1, H M L ; C 2, \text { high }}=\bar{r}\left(r_{t+1}^{C 1, \text { high;C2,high }}\right)-\bar{r}\left(r_{t+1}^{C 1, \text { low } ; C 2, \text { high }}\right) \\
\overline{\Delta \bar{r}^{C 1, H M L ; C 2, l o w}}=r \\
\left.. r_{t+1}^{C 1, \text { high;C2,low }}\right)-\bar{r}\left(r_{t+1}^{C 1, \text { low } ; C 2, \text { low }}\right)
\end{gathered}
$$

are the average return differentials of the HML portfolios. Otherwise, we obtain contradicting averages yielding insignificant results. Because the test statistic includes minimum or maximum functions, according to Patton and Timmermann (2010) we should only find a distribution for the test statistic $\mathrm{J}$ in case of specially distributed returns. Hence, Patton and Timmermann (2010) suggest following Politis and Romano (1994), by calculating p-values with the help of a stationary bootstrap approach. The central idea of the bootstrap approach is to draw crosssectional dependencies thus preserving returns data in blocks, where the starting and end points of the series are random. The block length is generated by a geometric distribution. As recommended by Patton and Timmermann (2010), we use an average block length of ten months, and specifically for our case we employ 10,000 bootstrap replications, to prevent Monte Carlo errors from influencing p-values (Monotonic relation test or MR test). Furthermore, we apply these methodologies for all combinations of characteristics and variables specified below.

We implement these portfolio compositions for all metals at once. To improve robustness (see section 4) and to identify possible distinctions and characteristics among these main groups of metals, two classifications are applied: exchange-traded or non-exchange-traded metals, and precious metals or non-precious metals, respectively. For the specific classification of each metal, see Table 1. 


\subsection{Data}

As this paper intends to present an analysis that is as extensive as possible, our main priority is to obtain data for many different metals. Overall, our analysis uses prices and variables for 30 different metals, as outlined in Table 1, and comprises the most economically important metals, in a sample period from 1990 to 2013.

To generate specific results for every metal, we mostly restrict our variables to metal-specific characteristics, which allow portfolio building and provide a broad availability of data across many or all metals, thereby enabling a cross-sectional analysis. These variables are in most cases only available in an annual frequency, which is why we optimize our method to deal with this small number of observations (see below). Non metal-specific macroeconomic data are used to complement these results and to control for macroeconomic influence.

Monthly price data and yearly data on reserves and country concentration are obtained from the German Federal Institute for Geosciences and Natural Resources (BGR) as a proprietary data set. The source for the remaining fundamental data (world mine production, U.S. apparent consumption, U.S. secondary production, and U.S. stocks) is the United States Geological Survey (USGS). For the USGS variables, the respective units are metric tons, while the units of the BGR data vary and are presented in the legend of Table 1 . The HHI uses squared percentage points $(0 \ldots 10.000)$ as unit, as is quite common. Table 1 also presents descriptive statistics for our price data, including mean, standard deviation, skewness, kurtosis, and Jarque-Bera statistics for absolute prices and log returns. It is noteworthy that these figures strongly suggest prices and returns are not normally distributed, which also applies to all fundamental variables with only some isolated exceptions (hence we do not present the JarqueBera statistics for the fundamental variables, as they provide no specific information). Therefore, a portfolio aggregation of returns, as described in our method section as well as a non-parametric statistical method as used in this paper, is highly advisable and provides additional robustness.

In addition, macroeconomic variables are obtained from various sources like the World Bank or the Federal Reserve Bank (see Table 2). These variables are constructed according to Ahumada and Cornejo (2015). We approximate monthly GDP data from the most recent quarterly observation by the price-output ratio using the MSCI world index (see Rangvid 2006).

Most data are available from 1990 up to 2013. Some variables, like the value factor, use prices of a few preceding years; therefore, the first prices used in our analysis come from 1984. The exact number of data points is presented in Table 1, Table 3, and Table 4, along with values for mean and standard deviation. Table 4 again presents values for skewness, kurtosis, and Jarque-Bera statistics of macroeconomic variables, where three variables could 
potentially be normally distributed. Overall, the extent of our data is unique in this context and provides a promising foundation for new scientific insights on the determinants of expected returns of metal prices.

Table 1: Descriptive statistics for metal prices

\begin{tabular}{|c|c|c|c|c|c|c|}
\hline Metal & Mean & SD & Skewness & $\begin{array}{c}\text { Excess } \\
\text { Kurtosis }\end{array}$ & JB statistic & JB statistic (log returns) \\
\hline$\overline{A g^{*} \text { (silver) }}$ & 9.51 & 8.19 & 2.02 & 3.28 & 408.01 & 57.18 \\
\hline$A l$ (aluminium) & 1712.07 & 493.86 & 0.87 & 0.18 & 46.00 & 215.11 \\
\hline As (arsenic) & 1.32 & 0.29 & 0.76 & 0.64 & 29.88 & 11313.88 \\
\hline$A u^{*}($ gold $)$ & 567.06 & 399.44 & 1.73 & 1.73 & 224.10 & 45.84 \\
\hline Bi (bismuth) & 11672.44 & 7289.71 & 1.59 & 2.01 & 212.49 & 544.07 \\
\hline Cd (cadmium) & 3.49 & 3.73 & 2.27 & 5.08 & 701.61 & 302.23 \\
\hline Co (cobalt) & 37367.32 & 18598.00 & 1.09 & 1.69 & 114.52 & 431.85 \\
\hline $\mathrm{Cr}$ (chromium) & 1591.67 & 904.02 & 2.20 & 6.64 & 959.43 & 2147.26 \\
\hline $\mathrm{Cu}$ (copper) & 3517.11 & 2428.04 & 1.11 & -0.30 & 74.99 & 260.15 \\
\hline Ge (germanium) & 621536.68 & 326766.18 & 0.92 & -0.28 & 51.78 & 36911.28 \\
\hline $\mathrm{Hg}^{*}$ (mercury) & 535.55 & 775.53 & 2.71 & 6.64 & 1110.24 & 2255.93 \\
\hline In (indium) & 355877.67 & 244725.98 & 0.89 & -0.13 & 47.81 & 1233.23 \\
\hline Li (lithium) & 3071.09 & 1821.84 & 1.03 & -0.65 & 68.87 & 19721.35 \\
\hline Mg (magnesium) & 2796.12 & 747.24 & 0.84 & 1.51 & 77.88 & 7331.42 \\
\hline Mn (manganese) & 762.65 & 510.89 & 2.25 & 6.16 & 879.30 & 15306.74 \\
\hline Mo (molybdenum) & 22609.05 & 22515.94 & 1.51 & 1.06 & 152.49 & 8835.59 \\
\hline$N i($ nickel) & 11739.93 & 8120.81 & 1.83 & 4.18 & 467.15 & 500.45 \\
\hline$P b($ lead $)$ & 984.90 & 725.54 & 1.40 & 0.83 & 127.29 & 94.78 \\
\hline$P d^{*}$ (palladium) & 288.92 & 212.11 & 1.23 & 0.47 & 92.94 & 147.38 \\
\hline$P t^{*}($ platinum $)$ & 751.99 & 474.35 & 1.11 & -0.09 & 73.16 & 1405.71 \\
\hline $\mathrm{Rh}^{*}$ (rhodium) & 2392.33 & 2086.65 & 1.78 & 2.58 & 140.95 & 545.94 \\
\hline Sb (antimony) & 3998.09 & 3475.82 & 1.81 & 2.49 & 290.61 & 538.31 \\
\hline Si (silicon) & 804.80 & 326.44 & 2.54 & 7.91 & 1248.29 & 8146.86 \\
\hline$S n(t i n)$ & 9624.86 & 6198.23 & 1.47 & 1.12 & 148.89 & 162.63 \\
\hline Ta (tantalum) & 662.47 & 478.74 & 2.23 & 5.66 & 784.26 & 2864.06 \\
\hline $\mathrm{Ti}$ (titanium) & 78413.45 & 47253.06 & 6.10 & 42.46 & 27647.76 & 43316.90 \\
\hline $\mathrm{V}$ (vanadium) & 100.56 & 56.57 & 2.61 & 6.69 & 1086.24 & 129192.90 \\
\hline W (tungsten) & 22.12 & 16.37 & 2.54 & 9.39 & 1728.76 & 723.63 \\
\hline Zn (zinc) & 103.05 & 89.40 & 1.53 & 1.22 & 163.01 & 1193.55 \\
\hline $\mathrm{Zr}$ (zirconium) & 1395.44 & 692.28 & 1.73 & 3.22 & 337.33 & 50.89 \\
\hline
\end{tabular}

Note: This table provides an overview of the metals analyzed. Price data are taken from the German Federal Institute for Geosciences and Natural Resources (BGR). The sample period is from January 1990 (or July 1984 for out of sample figures, like value) to December 2013, with a monthly sample frequency. Furthermore, metals belonging to the category of exchange-traded metals (either LME or CME Group) are italicized. Precious metals are marked with *. Furthermore, it displays the mean, standard deviation (SD), skewness, excess kurtosis and Jarque-Bera (JB) test statistics of the monthly prices as well as additional Jarque-Bera test statistics for the log returns for the metals considered. Prices use following units: US\$/t: Al, Cu, In, Li, Mg, Ni, Pb, Sb, Si, Sn, Ta, Ti, Zn, Zr; US\$/kg: As, Bi, Cd, Co, Cr, Ge, Mo, V; US\$/troz: Ag, Au, Pd, Pt, Rh; US\$/flask: Hg; €/t: Mn, RMB/t: W. The number (\#) of data points is 354 except for arsenic (258), rhodium (168), silicon (330) and titanium (330). 
Table 2: Overview of fundamental variables

\begin{tabular}{|c|c|c|}
\hline Name & Description & Data source \\
\hline \multicolumn{3}{|c|}{ Fundamental variables } \\
\hline HHI Country & $\begin{array}{l}\text { The Herfindahl-Hirschman Index of producing countries, } \\
\text { i.e. the global sum of squares of the market shares of } \\
\text { producing countries (in percent points). }\end{array}$ & $\begin{array}{l}\text { German Federal Institute for } \\
\text { Geosciences and Natural Resources } \\
\text { (BGR) }\end{array}$ \\
\hline Reserves & Global known and probable reserves. & BGR \\
\hline MineProd & Global mine production. & $\begin{array}{l}\text { United States Geological Survey } \\
\text { (USGS) }\end{array}$ \\
\hline AppConsum & Apparent consumption in the United States. & USGS \\
\hline 2Prod & Secondary production in the United States. & USGS \\
\hline Stocks & Aggregated Stocks in the United States. & USGS \\
\hline \multicolumn{3}{|c|}{ Macroeconomic variables } \\
\hline World GDP & $\begin{array}{l}\text { World gross domestic product at market prices (US\$). We } \\
\text { define a monthly GDP series from the most recent quarterly } \\
\text { (seasonally adjusted annual rate) observation. }\end{array}$ & $\begin{array}{l}\text { The World Bank (Global Economic } \\
\text { Monitor) }\end{array}$ \\
\hline $\begin{array}{l}\text { World Industrial } \\
\text { Production }\end{array}$ & World Industrial production index seasonally adjusted & $\begin{array}{l}\text { The World Bank (Global Economic } \\
\text { Monitor) }\end{array}$ \\
\hline World Inflation & World Core CPI seasonally adjusted & $\begin{array}{l}\text { The World Bank (Global Economic } \\
\text { Monitor) }\end{array}$ \\
\hline Treasury Rate & One-year US treasury constant maturity rate & Federal Reserve Bank of St. Louis \\
\hline Exchange Rate & Broad effective exchange rate for the US & Federal Reserve Bank of St. Louis \\
\hline $\begin{array}{l}\text { Global Market } \\
\text { Factor }\end{array}$ & $\begin{array}{l}\text { Global market factors includes stocks from } 23 \text { countries } \\
\text { worldwide }\end{array}$ & Kenneth R. French's Data Library \\
\hline GSCI All Metals & $\begin{array}{l}\text { S\&P Goldman Sachs Commodity Index (GSCI) All Metals } \\
\text { Index }\end{array}$ & S\&P Dow Jones Indices \\
\hline LMEX Index & $\begin{array}{l}\text { London Metal Exchange Index (LMEX) including LME's six } \\
\text { primary non-ferrous metals }\end{array}$ & London Metal Exchange (LME) \\
\hline
\end{tabular}

Note: This table provides an overview of the fundamental factors or characteristics included in our study. 
Table 3: Descriptive statistics of metal-specific fundamental factors

\begin{tabular}{|c|c|c|c|c|c|c|c|c|c|c|c|c|}
\hline \multirow{2}{*}{$\begin{array}{c}\text { Variable } \\
\text { Metal }\end{array}$} & \multicolumn{2}{|c|}{ HHI Country } & \multicolumn{2}{|c|}{ Reserves } & \multicolumn{2}{|c|}{ MineProd } & \multicolumn{2}{|c|}{ AppConsum } & \multicolumn{2}{|c|}{ 2Prod } & \multicolumn{2}{|c|}{ Stocks } \\
\hline & Mean & SD & Mean & SD & Mean & SD & Mean & SD & Mean & SD & Mean & SD \\
\hline $\mathrm{Ag}$ & 916.26 & 76.13 & 308.76 & 83.25 & 18954.17 & 3449.88 & 5747.08 & 1249.06 & 1186.68 & 521.43 & 2841.76 & 1637.43 \\
\hline $\mathrm{Al}$ & 1136.38 & 449.27 & 24602.33 & 2083.14 & 29087500.00 & 9332796.67 & 5418333.33 & 1090300.67 & 3187500.00 & 474888.14 & 614701.09 & 863077.29 \\
\hline As & & & & & 41541.67 & 7091.66 & 15741.25 & 8556.84 & & & 75.70 & 0.00 \\
\hline $\mathrm{Au}$ & 873.00 & 279.86 & 45815.16 & 3632.10 & 2441.25 & 169.71 & 220.92 & 43.75 & 91.66 & 70.35 & & \\
\hline $\mathrm{Bi}$ & & & & & 5203.33 & 1710.52 & 1638.75 & 511.88 & & & 192.38 & 94.07 \\
\hline $\mathrm{Cd}$ & 955.08 & 357.66 & 572.55 & 69.23 & 20083.33 & 1343.71 & 1788.24 & 879.10 & & & 620.76 & 518.32 \\
\hline Co & 2179.41 & 1191.71 & 5556.96 & 1565.60 & 55875.00 & 28913.42 & 9623.33 & 1472.30 & 2140.00 & 445.30 & 1303.04 & 508.78 \\
\hline $\mathrm{Cr}$ & 2343.06 & 292.72 & 1648.49 & 1358.10 & 5277500.00 & 1648469.62 & 508083.33 & 112343.56 & 172125.00 & 20931.06 & 41973.33 & 41771.63 \\
\hline $\mathrm{Cu}$ & 1370.90 & 208.99 & 439269.06 & 126587.40 & 13278750.00 & 2748522.80 & 2370833.33 & 444540.18 & 316458.33 & 156794.71 & 327520.83 & 254148.23 \\
\hline $\mathrm{Ge}$ & 4672.72 & 2203.01 & & & 83.25 & 33.38 & 33.67 & 10.17 & & & 40.82 & 20.70 \\
\hline $\mathrm{Hg}$ & 2975.25 & 1182.64 & 106739.07 & 29595.08 & 1931.67 & 648.08 & 440.00 & 155.71 & 393.13 & 80.24 & 346.13 & 99.40 \\
\hline In & 2449.18 & 967.73 & & & 413.00 & 231.75 & 75.46 & 33.44 & & & 0.65 & 0.67 \\
\hline $\mathrm{Li}$ & 2500.31 & 457.59 & 5065233.82 & 3820120.46 & 298708.33 & 160125.86 & 2191.67 & 556.71 & & & & \\
\hline $\mathrm{Mg}$ & 2492.67 & 1145.38 & & & 511833.33 & 180532.47 & 136541.67 & 26539.25 & 26550.00 & 4268.10 & 22444.44 & 4192.88 \\
\hline $\mathrm{Mn}$ & 1554.50 & 569.54 & 618.98 & 141.41 & 9919166.67 & 3186101.22 & 741541.67 & 135797.02 & & & 1157166.67 & 543035.81 \\
\hline Mo & 2303.32 & 281.75 & 7050.36 & 2098.60 & 164966.67 & 53003.39 & 22104.17 & 5828.70 & & & 9789.17 & 5645.44 \\
\hline $\mathrm{Ni}$ & 1221.75 & 159.84 & 56819.73 & 12307.86 & 1346416.67 & 315751.47 & 208333.33 & 20791.96 & 80466.67 & 16177.08 & 32083.33 & 15068.58 \\
\hline $\mathrm{Pb}$ & 1643.02 & 633.14 & 70033.39 & 9596.31 & 3484583.33 & 694993.88 & 1520000.00 & 141244.47 & 1051208.33 & 112053.55 & 81133.33 & 21064.06 \\
\hline $\mathrm{Pd}$ & 3719.43 & 485.19 & 67968.64 & 13855.81 & 396.08 & 81.63 & 219.13 & 45.33 & 4.76 & 0.95 & 22.37 & 24.11 \\
\hline $\mathrm{Pt}$ & 5928.84 & 405.95 & 67968.64 & 13855.81 & 396.08 & 81.63 & 219.13 & 45.33 & 4.76 & 0.95 & 22.37 & 24.11 \\
\hline $\mathrm{Rh}$ & & & 67968.64 & 13855.81 & 396.08 & 81.63 & 219.13 & 45.33 & 4.76 & 0.95 & 22.37 & 24.11 \\
\hline $\mathrm{Sb}$ & 6422.79 & 1075.17 & 2693.44 & 1080.32 & 135420.83 & 40370.16 & 34662.50 & 8560.90 & 7510.42 & 5356.98 & 6059.58 & 3971.48 \\
\hline $\mathrm{Si}$ & 2790.22 & 704.04 & & & 4750000.00 & 1599531.18 & 529000.00 & 118870.38 & & & 35954.17 & 16277.05 \\
\hline $\mathrm{Sn}$ & 2169.20 & 523.86 & 6511.19 & 1218.74 & 244083.33 & 35750.19 & 48104.17 & 6246.43 & 9067.92 & 2323.81 & 9570.00 & 2525.74 \\
\hline $\mathrm{Ta}$ & 2990.53 & 945.50 & 53950.34 & 44279.70 & 815.79 & 384.92 & 587.22 & 222.77 & 93.62 & 29.83 & & \\
\hline $\mathrm{Ti}$ & 1628.10 & 170.43 & & & & & 24704.55 & 8338.44 & & & 8548.33 & 5328.02 \\
\hline $\mathrm{V}_{-}$ & 3324.34 & 331.84 & 11071.31 & 2668.14 & 48108.33 & 15832.51 & 4917.50 & 1877.54 & & & 444.00 & 301.72 \\
\hline $\mathrm{W}_{-}$ & 6130.14 & 977.32 & 2583.83 & 397.31 & 51691.67 & 14120.93 & 12132.08 & 2669.27 & 4477.50 & 2282.33 & 2111.67 & 1059.15 \\
\hline $\mathrm{Zn}$ & 1095.62 & 209.61 & 189524.33 & 38144.15 & 9397500.00 & 2124745.57 & 1107583.33 & 148051.49 & 135500.00 & 16810.22 & 227704.17 & 121409.18 \\
\hline $\mathrm{Zr}$ & 2803.81 & 305.25 & & & 1037791.67 & 271808.45 & 151071.43 & 21802.57 & & & 28330.77 & 4818.30 \\
\hline
\end{tabular}

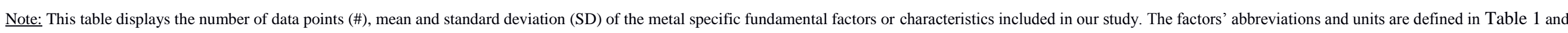

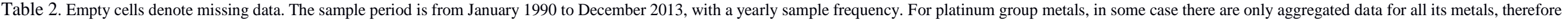

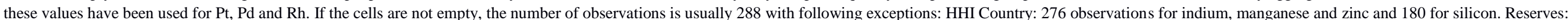

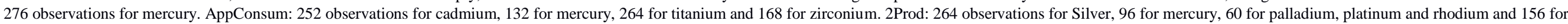
tantalum. Stocks: 252 observations for silver, 276 for aluminum, 12 for arsenic, 252 for cadmium, 276 for germanium, 96 for mercury, 120 for indium, 108 for magnesium and 156 for zirconium. 
Table 4: Summary statistics of fundamental macroeconomic factors

\begin{tabular}{|c|c|c|c|c|c|c|}
\hline Variable & \# & Mean & SD & Skewness & Kurtosis & Jarque-Bera statistics \\
\hline World GDP (Seas. adj., indexed) & 206 & -9.15 & 0.27 & -0.32 & -0.34 & 4.38 \\
\hline World Industrial Production (US\$ per month) & 218 & $1.27 \mathrm{E}+12$ & $1.84 \mathrm{E}+11$ & 0.17 & -1.26 & 15.52 \\
\hline Treasury Rate $(\%)$ & 354 & 4.35 & 2.77 & 0.07 & -0.67 & 6.79 \\
\hline Exchange Rate (Indexed to 100, 2010) & 240 & 105.54 & 10.50 & 0.20 & -0.89 & 9.41 \\
\hline World Inflation (Indexed to 100, 2010) & 218 & 90.88 & 9.35 & 0.0074 & -1.17 & 12.46 \\
\hline Global Market Factor (monthly change) & 282 & 0.45 & 4.46 & -0.73 & 1.52 & 53.98 \\
\hline LMEX Index & 353 & 1915.23 & 999.27 & 1.06 & -0.28 & 67.81 \\
\hline GSCI All Metals & 227 & 133.02 & 65.45 & 0.52 & -1.35 & 27.52 \\
\hline
\end{tabular}

Note: This table displays the number of data points (\#), mean, standard deviation (SD), skewness, kurtosis and Jarque-Bera statistics of the monthly changes for fundamental macroeconomic factors or characteristics included in our study. We approximate monthly GDP data from the most recent quarterly observation by the price-output ratio using the MSCI world index (see Rangvid 2006). The factors' abbreviations and units are defined in Table 2. The sample period is from January 1990 to December 2013.

\subsection{Variables and transformations}

The most important utilized transformations and figures are presented in Table 5. In this list, characteristics are sorted according to monthly (Panel A), yearly (Panel B), or constant frequency (Panel C).

\section{Table 5: Variables and transformations}

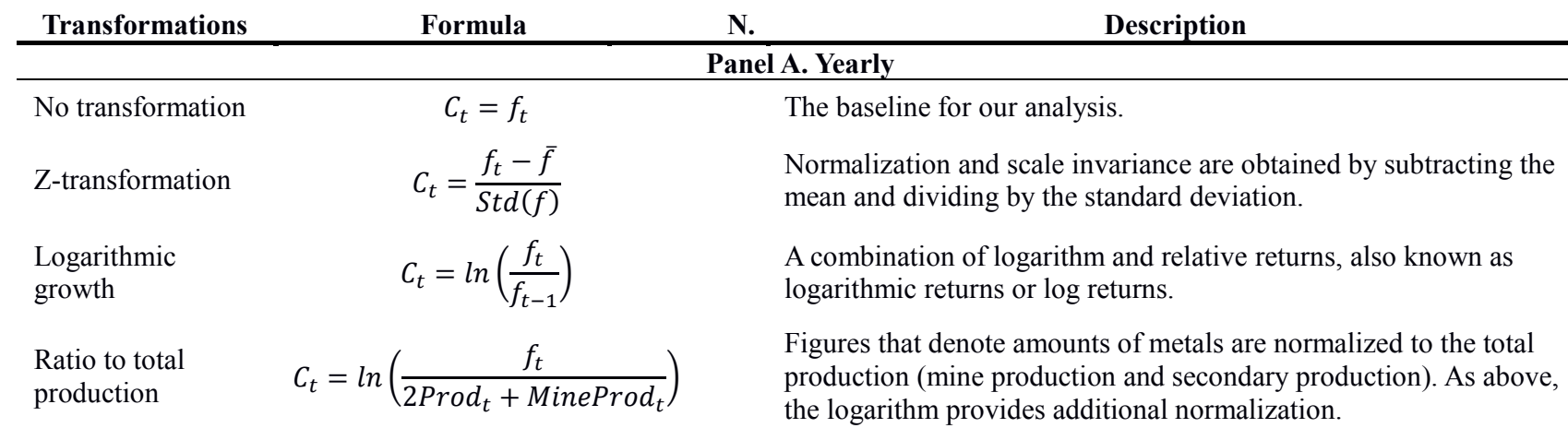


Table 5: Variables and transformations (continued)

\begin{tabular}{|c|c|c|}
\hline Variables & Formula & Description \\
\hline \multicolumn{3}{|r|}{ Panel B. Monthly } \\
\hline value & $C_{t}=\ln \left(\frac{\left(\sum_{s=t-66}^{t-54} P_{s}\right) / 13}{P_{t}}\right)$ & $\begin{array}{l}\text { "Value" is the logarithmic inverse return within a } 5 \text { year time } \\
\text { frame. As timespans of these cycles may vary, we additionally use } \\
\text { historical prices from } 4 \text { and } 6 \text { years ago. The historical price is } \\
\text { calculated as the mean of the month exactly } 4,5 \text {, or } 6 \text { years past } \\
\text { and } 6 \text { months before and after, for each. }\end{array}$ \\
\hline momentum & $C_{t}=\sum_{s=t-\text { timeframe }}^{t-1} \ln \left(\frac{P_{s}}{P_{s-1}}\right)$ & $\begin{array}{l}\text { "Momentum" is the sum of the logarithmic returns within the } \\
\text { short-term past. We use the last } 12 \text { months and last } 6 \text { months as } \\
\text { these past timeframes. }\end{array}$ \\
\hline $\begin{array}{l}\text { momentum } \\
2\end{array}$ & $C_{t}=\sum_{s=t-11}^{t-6} \ln \left(\frac{P_{s}}{P_{s-1}}\right)$ & $\begin{array}{l}\text { We also measure momentum regarding the last } 7 \text { to } 12 \text { months, } \\
\text { which includes a gap of } 6 \text { months in relation to the current price, } \\
\text { (Novy-Marx (2012)). }\end{array}$ \\
\hline \multicolumn{3}{|r|}{ Panel C. Constant } \\
\hline CAPM Beta & $\begin{array}{c}C=\beta \\
\left(r_{t}=\alpha+\beta r_{t}^{m}+\varepsilon_{t}\right)\end{array}$ & $\begin{array}{l}r_{t} \text { - excess return: } \log \text { return in excess of the one-month U.S. } \\
\text { treasury rate (obtained from Kenneth R. French's website) } \\
r_{t}^{m} \text { - excess market return: } \log \text { return of the "market portfolio" in } \\
\text { excess of the one-month U.S. treasury rate }\end{array}$ \\
\hline Macro Beta & $\begin{array}{c}C=\beta \\
\left(r_{t}=\alpha+\beta r_{t}^{m a}+\varepsilon_{t}\right)\end{array}$ & $\begin{array}{l}r_{t} \text { - excess return: } \log \text { return in excess of the one-month U.S. } \\
\text { treasury rate } \\
r_{t}^{m a}-\text { differences in macroeconomic variables: monthly change of } \\
\text { world GDP, industrial production, exchange rate, world inflation or } \\
\text { treasury rate. }\end{array}$ \\
\hline
\end{tabular}

Note: This table provides an overview of the variables and their respective transformations employed in our study.

For yearly data (Panel A), besides the original type of a characteristic, the central transformations are the $\mathrm{z}$ transformation, logarithmic growth, and the ratio to total production, according to e.g. Arango et al. (2012), Coleman (2012), or Frankel (2008). In contrast to fundamental data, which are only available on a yearly basis, we obtain monthly data for financial figures in Panel B. The most important characteristic in this category is "value", which is widely cited in the finance literature (e.g. Asness et al. 2013). Value is the logarithm of the inverse return for a five-year time frame. The rationale for value as a factor for average returns is the assumption of a mean reverting nature (e.g. Pindyck 1978) of (metal) prices: if an asset has had a negative return within the last five years, it could presumably soon change for the better. In relation to the microeconomics of resource markets, it can be argued that a longer downturn in resources prices could lead to cuts in production capacities. Due to tightened supply, price increases may follow. This characteristic performs well if there is a cyclical nature of prices. As the timespan of these cycles varies, we calculate the value for 4 and 6 years of historic data.

A similar capital market phenomenon is known as momentum, which is related to the returns of an asset in the recent past. Momentum is the sum of the logarithmic returns within a certain time frame. The assumption is that if an asset has had very positive returns for some time, it may have some momentum that carries its performance on. The existence of momentum is partly seen as a proof of market inefficiency or irrational behavior according to the financial literature (Fama and Litterman 2012, p. 18). This effect is also observed for several commodities 
from various asset classes (e.g. Erb and Harvey 2006; Asness et al. 2013), but not for the broad range of metals in our sample. From a resource-market perspective, this can be seen as an ongoing increase in demand, which in the short run cannot be met by inventories or production increases. In addition to the standard momentum measure proposed by Jegadeesh and Titman (1993), which incorporates the last 12 respective months, we also utilize the momentum of the last 6 months and the momentum of the last 7 to 12 months (which includes a gap of 6 months in relation to the current price). These figures are, for instance, examined by Novy-Marx (2012).

Panel C of Table 5 includes constant characteristics, where the respective figures do not vary over time. Consistent with the transformations in Panel A, we also apply logarithms to constant characteristics as a basis for calculating the betas. To explicate the method, we first concentrate on the CAPM beta, $\beta$. This important figure in the context of asset pricing represents systematic risk and is worthwhile to examine. Usually assets with a high beta show higher than average returns. To determine $\beta$, we conduct the following regression model:

$$
r_{t}=\alpha+\beta r_{t}^{m}+\varepsilon_{t}
$$

Where $r_{t}$ represents the excess return, that is, the return in excess of the one-month U.S. Treasury bill rate (obtained from Kenneth R. French's website), and $r_{t}^{m}$ is the excess market return, i.e., the log return on the "market portfolio" in excess of the one-month U.S. Treasury bill rate. We use four different portfolios or indices as proxies for the market portfolio: a portfolio that contains all metals included in this study, weighted equally; the GSCI all metals index; the LMEX index; and the global market factor of Fama and French (2012) (see Table 2). Hence, our analysis employs four different $\beta$-factors, as $r_{t}^{m}$ is determined in four different ways.

In addition to the CAPM beta, we furthermore consider betas with respect to the changes in the macroeconomic variables, presented in Table 2. Here, consistent with current methodology, we compute the first differences of each of the aforementioned variables to proxy for their innovations according to Lutzenberger (2014).

\section{Empirical Results}

\subsection{Univariate Results}

Results for the univariate analysis are presented in Table 6. Overall, the results strongly differ for the respective panels A, B, and C. In Panel A (monthly sorts using financial key figures), 3 of 6 sorting characteristics show a large and highly significant predictive power for expected returns. In Panel B (yearly sorts using fundamental metal-specific variables), only 4 of 24 sorting characteristics are able to predict expected returns with some significance. Lastly, Panel C (monthly/quarterly sorts using macroeconomic variables) provides only 1 significant 
sorting characteristic among 9 characteristics. Thus, financial key figures seem to be superior in predicting expected returns.

In detail in Panel A, both variables value and momentum are very useful predictors: Value performs best for a 6 year interval, in which the factor portfolio shows highly significant returns of $0.94 \%$ per month, summing to about $11.3 \%$ per year. Value for 5 years is still highly significant, although with somewhat smaller returns, while value for 4 years is not significant at all. As the value variable stands for a kind of cyclicity, it seems that economic cycles for metals are at least 5 or 6 years long or perhaps even longer.

On the other hand, the momentum variable shows best results for the shortest periods, i.e. 2-6 months. Here, the factor portfolio exhibits $0.77 \%$ monthly returns on a high level of significance, summing to about $9.2 \%$ return per year. In contrast, both other momentum characteristics provide no significant results at all. Therefore, the momentum effect for metals seems to be limited to about half a year, while the value effect, which has an opposite impact, only becomes evident after about 5 years. Thus, in the short term, there is a positive autocorrelation of prices or returns, respectively, while in the long term, there is a negative autocorrelation.

Regarding the fundamental metal-specific variables, there are a few interesting results: 4 of 6 variables provide a significant result in exactly one transformation each, while two other variables (AppConsum and reserves) show no significant results at all. Specifically, secondary production (2Prod) shows weak significance when looking at the logarithmic growth. Metals with a high change in recycling amounts provide higher expected returns. Usually, high recycling rates would be associated with lower prices due to higher supply. Other explanations, like some indirect momentum effect (high prices lead to high returns, but high recycling as well) or recycling as early indicator would be possible, but are not fully convincing. The same applies to the HHI and Stocks: they both show significance for one transformation, but their directions of influence are prima facie counterintuitive; positive changes in the HHI (log growth) lead to low returns, while a high country concentration should usually increase prices due to monopolistic market structures. Here, a shakeout could be responsible for leaving only those countries producing with the lowest production costs, and therefore reducing prices (as can currently be observed in the oil markets). The same problem applies to Stocks: When related to the total production (a very sensible transformation, especially for stocks: This percentage indicates how long supply shortages can be withstood.), they significantly are related to positive returns. Thus, high stocks (in relation to total production) correlate with high returns, while usually a high inventory stock leads to decreasing prices. One possible explanation could be speculators stocking up, because they are awaiting future price increases. Lastly, the total world production (MineProd) predicts expected returns with high significance and an intuitive direction of influence: metals with 
relatively high production (z-transformation) exhibit low expected returns, as would be expected due to rising supply. As the z-transformation shows deviation from the long-term average, this effect is comparable to the value effect and can be attributed to cyclicity. Thus, all in all, while the world production is definitely an important variable for predicting expected returns, the state of the other fundamental metal-specific variables remains ambiguous due to their few and weak significances.

The same is true for the macroeconomic variables, where even fewer significant results can be observed, as only the Treasury rate is able to predict expected returns to some degree: metals positively correlated with the treasury rate (e.g. industrial metals like chromium or nickel) tend to have lower expected returns and vice versa. All other macroeconomic variables are not useful for predicting expected returns, as they show no significant results. 
Table 6: Characteristic-sorted metal portfolios

\begin{tabular}{|c|c|c|c|c|c|c|}
\hline \multicolumn{7}{|c|}{ Panel A: Monthly sorts } \\
\hline Sorting characteristic & & $\mathrm{P}_{1}$ & $\mathrm{P}_{2}$ & $\mathrm{P}_{3}$ & $\mathrm{P}_{3}-\mathrm{P}_{1}$ & Factor \\
\hline \multirow{2}{*}{ Value ( 5 years) } & Mean Return & $-0,45 \% *$ & $0,22 \%$ & $0,20 \%$ & $0,64 \% * * *$ & $0,68 \% * * *$ \\
\hline & Avg. Com. & 9,58 & 9,69 & 9,58 & 19,16 & 28,85 \\
\hline \multirow{2}{*}{ Value (4 years) } & Mean Return & $-0,22 \%$ & $0,13 \%$ & $0,08 \%$ & $0,30 \%$ & $0,37 \%$ \\
\hline & Avg. Com. & 9,62 & 9,69 & 9,62 & 19,27 & 28,93 \\
\hline \multirow{2}{*}{ Value (6 years) } & Mean Return & $-0,56 \% * *$ & $0,26 \%$ & $0,40 \% * *$ & $0,96 \% * * *$ & $0,94 \% * * *$ \\
\hline & Avg. Com. & 9,16 & 9,27 & 9,16 & 18,75 & 27,60 \\
\hline \multirow{2}{*}{ Momentum (2-6) } & Mean Return & $-0,45 \% * *$ & $-0,02 \%$ & $0,39 \% *$ & $0,84 \% * * *$ & $0,77 \% * * *$ \\
\hline & Avg. Com. & 9,79 & 9,69 & 9,79 & 18,75 & 29,26 \\
\hline \multirow{2}{*}{ Momentum (2-12) } & Mean Return & $-0,29 \%$ & $0,19 \%$ & $0,02 \%$ & $0,31 \%$ & $0,37 \%$ \\
\hline & Avg. Com. & 9,77 & 9,69 & 9,77 & 18,75 & 29,22 \\
\hline \multirow{2}{*}{ Momentum (7-12) } & Mean Return & $-0,28 \%$ & $0,30 \%$ & $-0,09 \%$ & $0,18 \%$ & $0,17 \%$ \\
\hline & Avg. Com. & 9,77 & 9,69 & 9,77 & 18,75 & 29,23 \\
\hline \multicolumn{7}{|c|}{ Panel B: Yearly sorts } \\
\hline Sorting characteristic & & $\mathrm{P}_{1}$ & $\mathrm{P}_{2}$ & $\mathrm{P}_{3}$ & $\mathrm{P}_{3}-\mathrm{P}_{1}$ & Factor \\
\hline \multirow{2}{*}{ 2Prod } & Mean Return & $0,08 \%$ & $0,03 \%$ & $-0,01 \%$ & $-0,10 \%$ & $-0,13 \%$ \\
\hline & Avg. Com. & 4,78 & 4,70 & 4,78 & 18,43 & 14,26 \\
\hline \multirow{2}{*}{ 2Prod (z-transformation) } & Mean Return & $-0,01 \%$ & $0,27 \%$ & $-0,14 \%$ & $-0,13 \%$ & $-0,13 \%$ \\
\hline & Avg. Com. & 4,78 & 4,70 & 4,78 & 18,43 & 14,26 \\
\hline \multirow{2}{*}{ 2Prod (log growth) } & Mean Return & $-0,19 \%$ & $-0,12 \%$ & $0,47 \%$ & $0,65 \% *$ & $0,55 \% *$ \\
\hline & Avg. Com. & 4,70 & 4,65 & 4,70 & 18,39 & 14,04 \\
\hline \multirow[b]{2}{*}{ 2Prod (ratio to total production) } & Mean Return & $0,01 \%$ & $0,06 \%$ & $0,02 \%$ & $0,01 \%$ & $0,05 \%$ \\
\hline & Avg. Com. & 4,78 & 4,70 & 4,78 & 9,57 & 14,26 \\
\hline \multirow{2}{*}{ AppConsum } & Mean Return & $0,03 \%$ & $0,05 \%$ & $-0,10 \%$ & $-0,13 \%$ & $-0,13 \%$ \\
\hline & Avg. Com. & 9,43 & 9,39 & 9,43 & 18,43 & 28,26 \\
\hline \multirow[b]{2}{*}{ AppConsum (z-transformation) } & Mean Return & $0,06 \%$ & $-0,12 \%$ & $0,10 \%$ & $0,05 \%$ & $0,07 \%$ \\
\hline & Avg. Com. & 9,43 & 9,39 & 9,43 & 18,43 & 28,26 \\
\hline \multirow{2}{*}{ AppConsum (log growth) } & Mean Return & $-0,19 \%$ & $-0,07 \%$ & $0,25 \%$ & $0,44 \%$ & $0,44 \%$ \\
\hline & Avg. Com. & 9,39 & 9,30 & 9,39 & 18,39 & 28,09 \\
\hline \multirow{2}{*}{ AppConsum (ratio to total production) } & Mean Return & $0,12 \%$ & $-0,17 \%$ & $0,10 \%$ & $-0,03 \%$ & $0,06 \%$ \\
\hline & Avg. Com. & 4,78 & 4,70 & 4,78 & 9,57 & 14,26 \\
\hline \multirow{2}{*}{ HHI Country } & Mean Return & $-0,10 \%$ & $0,22 \%$ & $0,06 \%$ & $0,16 \%$ & $0,31 \%$ \\
\hline & Avg. Com. & 8,91 & 8,61 & 8,91 & 18,46 & 26,43 \\
\hline \multirow{2}{*}{ HHI Country (z-transformation) } & Mean Return & $0,05 \%$ & $0,14 \%$ & $-0,01 \%$ & $-0,05 \%$ & $-0,01 \%$ \\
\hline & Avg. Com. & 8,91 & 8,61 & 8,91 & 18,43 & 26,43 \\
\hline \multirow{2}{*}{ HHI Country (log growth) } & Mean Return & $0,33 \%$ & $0,06 \%$ & $-0,23 \%$ & $-0,56 \% *$ & $-0,53 \% *$ \\
\hline & Avg. Com. & 8,87 & 8,57 & 8,87 & 18,39 & 26,30 \\
\hline \multirow{2}{*}{ HHI Country (ratio to total production) } & Mean Return & $-0,04 \%$ & $-0,02 \%$ & $0,20 \%$ & $0,23 \%$ & $0,23 \%$ \\
\hline & Avg. Com. & 4,78 & 4,70 & 4,78 & 14,30 & 14,26 \\
\hline \multirow{2}{*}{ Mine Prod } & Mean Return & $0,07 \%$ & $0,07 \%$ & $-0,10 \%$ & $-0,17 \%$ & $-0,21 \%$ \\
\hline & Avg. Com. & 9,52 & 1119,30 & 1119,52 & 18,43 & 28,35 \\
\hline \multirow{2}{*}{ Mine Prod (z-transformation) } & Mean Return & $0,19 \%$ & $0,23 \%$ & $-0,38 \%$ & $-0,57 \% * * *$ & $-0,66 \% * * *$ \\
\hline & Avg. Com. & 9,52 & 9,30 & 9,52 & 18,43 & 28,35 \\
\hline & Mean Return & $-0,10 \%$ & $-0,02 \%$ & $0,20 \%$ & $0,30 \%$ & $0,36 \%$ \\
\hline Mine Prod (log growth) & Avg. Com. & 9,52 & 9,30 & 9,52 & 18,39 & 28,35 \\
\hline & Mean Return & $0,02 \%$ & $0,06 \%$ & $0,01 \%$ & $-0,01 \%$ & $-0,05 \%$ \\
\hline Mine Prod (ratio to total production) & Avg. Com. & 4,78 & 4,70 & 4,78 & 9,57 & 14,26 \\
\hline
\end{tabular}


Table 6: Characteristic-sorted metal portfolios (continued)

\begin{tabular}{|c|c|c|c|c|c|c|}
\hline \multicolumn{7}{|c|}{ Panel B: Yearly sorts (continued) } \\
\hline Sorting characteristic & & $\mathrm{P}_{1}$ & $\mathrm{P}_{2}$ & $\mathrm{P}_{3}$ & $\mathrm{P}_{3}-\mathrm{P}_{1}$ & Factor \\
\hline \multirow{2}{*}{ Stocks } & "Mean Return & $-0,01 \%$ & $0,19 \%$ & $-0,07 \%$ & $-0,05 \%$ & $-0,19 \%$ \\
\hline & Avg. Com. & 7,57 & 7,83 & 7,57 & 18,43 & 22,96 \\
\hline \multirow{2}{*}{ Stocks (z-transformation) } & Mean Return & $-0,08 \%$ & $-0,08 \%$ & $0,23 \%$ & $0,31 \%$ & $0,37 \%$ \\
\hline & Avg. Com. & 7,57 & 7,83 & 7,57 & 18,43 & 22,96 \\
\hline \multirow{2}{*}{ Stocks (log growth) } & Mean Return & $0,17 \%$ & $-0,13 \%$ & $0,08 \%$ & $-0,08 \%$ & $-0,30 \%$ \\
\hline & Avg. Com. & 7,43 & 7,57 & 7,43 & 18,39 & 22,43 \\
\hline \multirow{2}{*}{ Stocks (ratio to total production) } & Mean Return & $-0,18 \%$ & $0,15 \%$ & $0,28 \%$ & $0,46 \% *$ & $0,37 \% *$ \\
\hline & Avg. Com. & 4,17 & 3,65 & 4,17 & 9,57 & 12,00 \\
\hline \multirow{2}{*}{ Reserves } & Mean Return & $0,07 \%$ & $0,00 \%$ & $0,04 \%$ & $-0,03 \%$ & $0,14 \%$ \\
\hline & Avg. Com. & 7,00 & 7,52 & 7,00 & 18,46 & 21,52 \\
\hline \multirow[b]{2}{*}{ Reserves (z-transformation) } & Mean Return & $0,27 \%$ & $-0,25 \%$ & $0,16 \%$ & $-0,11 \%$ & $-0,19 \%$ \\
\hline & Avg. Com. & 7,00 & 7,52 & 7,00 & 18,43 & 21,52 \\
\hline \multirow{2}{*}{ Reserves (log growth) } & Mean Return & $0,03 \%$ & $0,15 \%$ & $-0,08 \%$ & $-0,11 \%$ & $-0,13 \%$ \\
\hline & Avg. Com. & 7,00 & 7,48 & 7,00 & 18,39 & 21,48 \\
\hline \multirow{2}{*}{ Reserves (ratio to total production) } & Mean Return & $0,08 \%$ & $0,14 \%$ & $-0,04 \%$ & $-0,12 \%$ & $0,03 \%$ \\
\hline & Avg. Com. & 4,26 & 4,74 & 4,26 & 14,30 & 13,26 \\
\hline \multicolumn{7}{|c|}{ Panel C: Constant sorts } \\
\hline Sorting characteristic & & $\mathrm{P}_{1}$ & $\mathrm{P}_{2}$ & $\mathrm{P}_{3}$ & $\mathrm{P}_{3}-\mathrm{P}_{1}$ & Factor \\
\hline \multirow{2}{*}{ Beta (Commodity Index) } & Mean Return & $0,10 \%$ & $0,07 \%$ & $-0,07 \%$ & $-0,18 \%$ & $-0,07 \%$ \\
\hline & Avg. Com. & 10,00 & 10,00 & 10,00 & 20,00 & 30,00 \\
\hline \multirow{2}{*}{ Beta (GSCI All Metals) } & Mean Return & $0,05 \%$ & $0,04 \%$ & $0,03 \%$ & $-0,03 \%$ & $-0,09 \%$ \\
\hline & Avg. Com. & 10,00 & 10,00 & 10,00 & 20,00 & 30,00 \\
\hline \multirow{2}{*}{ Beta (LMEX Index) } & Mean Return & $0,09 \%$ & $0,16 \%$ & $-0,15 \%$ & $-0,23 \%$ & $-0,12 \%$ \\
\hline & Avg. Com. & 10,00 & 10,00 & 10,00 & 20,00 & 30,00 \\
\hline \multirow{2}{*}{ Beta (Global Market Factor) } & Mean Return & $0,15 \%$ & $-0,05 \%$ & $0,02 \%$ & $-0,13 \%$ & $-0,28 \%$ \\
\hline & Avg. Com. & 10,00 & 10,00 & 10,00 & 20,00 & 30,00 \\
\hline \multirow{2}{*}{ Beta (World GDP) } & Mean Return & $0,20 \%$ & $0,11 \%$ & $-0,23 \%$ & $-0,42 \% *$ & $-0,47 \%$ \\
\hline & Avg. Com. & 10,00 & 10,00 & 10,00 & 20,00 & 30,00 \\
\hline \multirow{2}{*}{ Beta (World Industrial Production) } & Mean Return & $0,17 \%$ & $-0,07 \%$ & $0,00 \%$ & $-0,17 \%$ & $-0,15 \%$ \\
\hline & Avg. Com. & 10,00 & 10,00 & 10,00 & 20,00 & 30,00 \\
\hline \multirow{2}{*}{ Beta (Treasury Rate) } & Mean Return & $0,30 \%$ & $-0,04 \%$ & $-0,15 \%$ & $-0,45 \% * *$ & $-0,81 \% * *$ \\
\hline & Avg. Com. & 10,00 & 10,00 & 10,00 & 20,00 & 30,00 \\
\hline \multirow{2}{*}{ Beta (Exchange Rate) } & Mean Return & $0,02 \%$ & $0,07 \%$ & $0,02 \%$ & $0,00 \%$ & $0,34 \%$ \\
\hline & Avg. Com. & 10,00 & 10,00 & 10,00 & 20,00 & 30,00 \\
\hline \multirow{2}{*}{ Beta (World Inflation) } & Mean Return & $0,02 \%$ & $0,18 \%$ & $-0,09 \%$ & $-0,11 \%$ & $-0,31 \%$ \\
\hline & Avg. Com. & 10,00 & 10,00 & 10,00 & 20,00 & 30,00 \\
\hline
\end{tabular}

Note: This table displays the results of metal portfolios formed monthly (Panel A), yearly (Panel B), and once (Panel C) according to a particular characteristic. The respective characteristic is shown in the first column of the table. P1, P2, and P3 contain the metals whose values for the respective characteristic are below the one-third, between the one-third and two-third, and above the two-third percentile, respectively, of the characteristic's sample distribution at the time of the portfolio formation. The first line associated with each characteristic shows the means of the monthly returns (in \%) and the second line denotes the number of metals contained in the respective portfolio on average (in brackets). Levels of statistical significance according to the Student's t-distribution are indicated by * (10\%), ** (5\%), and *** (1\%). The returns of P1, $\mathrm{P} 2$, and $\mathrm{P} 3$ are in excess of the one-month U.S. Treasury bill rate.

\subsection{Multivariate Results}

The multivariate results are presented in Table 7, Table 8, and Table 9. They are generally consistent with the univariate results, but account for some additional findings. Here, it is important to note that sequence of portfolio building matters. Table 7 shows an example: portfolios first sorted by value and then by the HHI (read from left to right) yield other results than portfolios with the inverse sorting sequence (read from top to bottom). In this example, there are noteworthy differences of about 20 to 50\%, and both sorts (value, HHI or HHI, value) show 
significant results. This is remarkable, as the untransformed $\mathrm{HHI}$ in the single sorts provides no significant results (see Table 5). Thus, this multivariate method could generate more results than the sum of its parts, while good results (like especially in the case of value and momentum) are still present, which substantiates the robustness of these results.

It is worth mentioning that - while the overall results are in line with the univariate method, e.g. financial variables performing especially well - there are some interesting differences, where the respective transformations play an important role. Generally, different kinds of variables seem to complement each other, especially financial and fundamental metal-specific variables, respectively. For instance, even Value4 yields several significant results when combined with fundamental metal-specific variables. However, the financial variables seem to play the major role in these combinations, as sorts on financial variables first are superior.

Regarding absolute values (see Table 8), the HHI performs especially well in combination with financial variables (value and momentum), and the treasury rate in combination with financial and fundamental metal-specific variables. The treasury rate is still significant when combined with almost all financial and fundamental metalspecific variables. Some statistical significances are found for the GDP, described below, as its results refer to all transformations.

Table 9 aggregates multiple results by presenting the median $\mathbf{J}$ statistic and its significance for each variable. As this aggregation involves a loss of information, this table is only complementary to the much larger non-aggregated tables. Most results are consistent with the univariate analysis, as is to be expected. In addition, AppConsum is significant for the log-growth transformation and GDP is marginally significant (p-value about 9.9\%) when combined with ratio variables. These results are in line with the multiple results above.

In addition, we also calculated the multivariate results using different transformations of fundamental metalspecific variables. When using z-transformed variables, reserves perform quite well when combined with financial variables. Additionally, the direction of influence is intuitive, as relatively high reserves are correlated with lower returns. This finding is genuinely new in relation to the univariate analysis and indicates that reserves do have some influence on the price, as it is to be expected for non-renewable resources like metals.

The log-growth transformation is especially intended for variables with percentage increases. Here, the absolute value contains less information than the relative change over one year. This applies to most fundamental metalspecific and many macroeconomic variables. Moreover, the HHI shows many significant results as in the univariate analysis, while the apparent consumption provides numerous, in part highly significant results. As in 
the case of reserves above, this is a genuinely new result in comparison with the univariate analysis. The direction of influence is also intuitive, as higher consumption in the U.S. leads to higher returns due to higher demand.

As it happens, the last transformation, ratio to total production, is primarily intended to be used for stocks. Indeed, stocks provide very high significances combined with almost all financial and financial factors, while only some macroeconomic variables offer significant combinations. Therefore, it seems clear that this transformation is most sensible for the stocks variable, and that stocks provide added value in combination with all but most macroeconomic variables.

Regarding macroeconomic variables, the GDP shows some new significances when combined with fundamental metal-specific variables in all transformations (absolute, z-transformation, log growth, ratio to total production), but most significant sorts have a negative sign. For instance, a relatively high GDP combined with world mine production correlates with lower returns. This can be attributed to the role of precious metals and metals in general as safe-haven investments in case of uncertain economic development.

Table 7: Example for two-sorted metal portfolios

\begin{tabular}{|c|c|c|c|c|c|}
\hline & & & & & \\
\hline & & \multicolumn{4}{|c|}{ HHI Country } \\
\hline & & $P_{x 1}($ Low $)$ & $\mathrm{P}_{\mathrm{x} 2}(\mathrm{High})$ & $\mathrm{P}_{\mathrm{x} 2}(\operatorname{High})-\mathrm{P}_{\mathrm{x} 1}($ Low $)$ & $\mathrm{J}$ statistic for monotonic relation \\
\hline \multirow{4}{*}{ 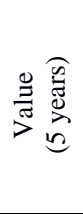 } & $\mathrm{P}_{1 \mathrm{x}}($ Low $)$ & $-0.28 \%$ & $-0.04 \%$ & $0.24 \%$ & \multirow{4}{*}{$0.24 \% *$} \\
\hline & $\mathrm{P}_{2 \mathrm{x}}(\mathrm{High})$ & $0.07 \%$ & $0.54 \%$ & $0.47 \%$ & \\
\hline & $\mathrm{P}_{2 \mathrm{x}}($ High $)-\mathrm{P}_{1 \mathrm{x}}($ Low $)$ & $0.35 \% *$ & $0.58 \% * *$ & & \\
\hline & $\begin{array}{l}\mathrm{J} \text {-statistic for monotonic } \\
\text { relation }\end{array}$ & \multicolumn{2}{|c|}{$0.35 \% * *$} & & \\
\hline
\end{tabular}

Note: This table displays the results of metal portfolios formed monthly according to characteristic value (5 years) and HHI country. The respective characteristics are shown in the first column and first line. The third and fourth line contain the portfolios below $\left(\mathrm{P}_{1 \mathrm{x}}\right)$ and above $\left(\mathrm{P}_{2 \mathrm{x}}\right)$ the median of the characteristics value; the third and fourth column the portfolios below $\left(\mathrm{P}_{\mathrm{x} 1}\right)$ and above $\left(\mathrm{P}_{\mathrm{x} 2}\right)$ the median of the characteristics HHI. The last line and the last column represent the J statistic for the monotonic relation according to formula (4). Levels of statistical significance according to the monotonic relation (MR) Test are indicated by * $(10 \%), * *(5 \%)$, and *** $(1 \%)$ text. The returns of all portfolios are in excess of the one-month U.S. Treasury bill rate. 
Table 8: Two-sorted metal portfolios based on absolute characteristic

\begin{tabular}{|c|c|c|c|c|c|c|c|c|c|c|c|c|c|c|c|c|c|c|c|c|c|}
\hline & 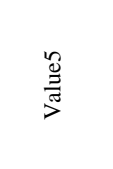 & 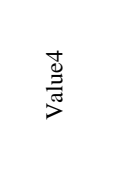 & 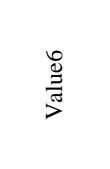 & 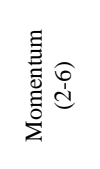 & 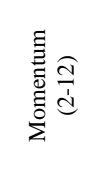 & 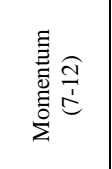 & $\begin{array}{l}\text { 㝵 } \\
\text { 言 } \\
\text { E्土 }\end{array}$ & 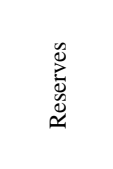 & 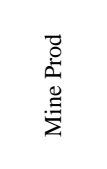 & 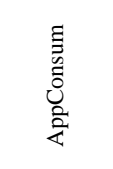 & : & $\begin{array}{l}\frac{n}{\ddot{c}} \\
\dot{c}\end{array}$ & 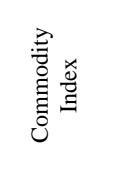 & 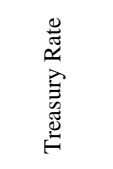 & 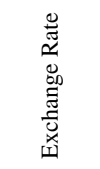 & $\begin{array}{l}\tilde{0} \\
0 \\
\overline{0} \\
0 \\
3\end{array}$ & 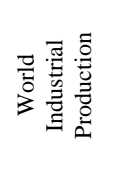 & 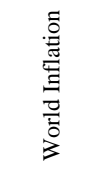 & 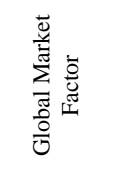 & 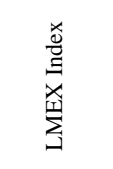 & 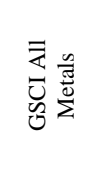 \\
\hline Value5 & $\mathrm{NaN}$ & $0,02 \%$ & $0,00 \%$ & $0,00 \%$ & $0,27 \% *$ & $0,49 \% * *$ & $0,35 \% * *$ & $0,13 \%$ & $0,15 \%$ & $0,46 \% * *$ & $0,37 \% * * *$ & $0,25 \%$ & $0,34 \% *$ & $0,45 \% * *$ & $0,42 \% * *$ & $0,35 \% *$ & $0,21 \% *$ & $0,22 \% *$ & $0,35 \% * *$ & $0,34 \% *$ & $0,34 \% *$ \\
\hline Value4 & $0,00 \%$ & $\mathrm{NaN}$ & $0,04 \%$ & $0,00 \%$ & $0,00 \%$ & $0,27 \% *$ & $0,17 \%$ & $0,00 \%$ & $0,09 \%$ & $0,11 \%$ & $0,28 \% *$ & $0,00 \%$ & $0,14 \%$ & $0,13 \%$ & $0,09 \%$ & $0,06 \%$ & $0,18 \% *$ & $0,15 \%$ & $0,07 \%$ & $0,14 \%$ & $0,14 \%$ \\
\hline Value6 & $0,29 \% *$ & $0,55 \% * *$ & $\mathrm{NaN}$ & $0,28 \% *$ & $0,58 \%$ ** & $0,67 \% * * *$ & $0,55 \% * * *$ & $0,49 \% * * * *$ & $0,68 \% * *$ & $0,58 \% * * *$ & $0,54 \% * * *$ & $0,72 \% * * *$ & $0,53 \% * * *$ & $0,61 \% * * *$ & $0,47 \% * *$ & $0,59 \% * *$ & $0,54 \% * *$ & $0,59 \% * *$ & $0,52 \% * *$ & $0,53 \% * * *$ & $0,53 \% * * * *$ \\
\hline $\begin{array}{l}\text { Momentum } \\
\quad(2-6)\end{array}$ & $0,20 \% *$ & $0,07 \%$ & $0,22 \% *$ & $\mathrm{NaN}$ & $0,20 \% *$ & $0,26 \% * *$ & $0,23 \% *$ & $0,51 \% * * *$ & $0,29 \% * *$ & $0,20 \% * *$ & $0,34 \% * * * *$ & $0,25 \% * *$ & $0,30 \% *$ & $0,62 \% * * *$ & $0,18 \%$ & $0,23 \% *$ & $0,46 \% * * * *$ & $0,51 \% * * *$ & $0,52 \% * * * *$ & $0,30 \% *$ & $0,30 \% *$ \\
\hline $\begin{array}{l}\text { Momentum } \\
\quad(2-12)\end{array}$ & $0,00 \%$ & $0,00 \%$ & $0,06 \%$ & $0,00 \%$ & $\mathrm{NaN}$ & $0,00 \%$ & $0,08 \%$ & $0,23 \% *$ & $0,16 \%$ & $0,24 \% *$ & $0,00 \%$ & $0,04 \%$ & $0,17 \%$ & $0,10 \%$ & $0,00 \%$ & $0,21 \%$ & $0,12 \%$ & $0,00 \%$ & $0,00 \%$ & $0,17 \%$ & $0,17 \%$ \\
\hline $\begin{array}{l}\text { Momentum } \\
\quad(7-12)\end{array}$ & $0,09 \%$ & $0,11 \%$ & $0,08 \%$ & $0,00 \%$ & $0,00 \%$ & $\mathrm{NaN}$ & $0,11 \%$ & $-0,04 \%$ & $0,00 \%$ & $0,00 \%$ & $-0,14 \%$ & $0,00 \%$ & $0,19 \%$ & $0,00 \%$ & $0,01 \%$ & $0,01 \%$ & $0,00 \%$ & $0,03 \%$ & $0,00 \%$ & $0,19 \% *$ & $0,19 \%$ \\
\hline HHI Country & $0,24 \% *$ & $0,29 \% * *$ & $0,32 \% * *$ & $0,02 \%$ & $0,32 \% * *$ & $0,31 \%$ ** & $\mathrm{NaN}$ & $0,12 \%$ & $0,09 \%$ & $0,09 \%$ & $0,00 \%$ & $0,00 \%$ & $0,04 \%$ & $0,11 \%$ & $0,00 \%$ & $0,07 \%$ & $0,00 \%$ & $0,05 \%$ & $0,04 \%$ & $0,04 \%$ & $0,04 \%$ \\
\hline Reserves & $0,00 \%$ & $0,00 \%$ & $0,00 \%$ & $0,01 \%$ & $0,05 \%$ & $0,03 \%$ & $0,10 \%$ & $\mathrm{NaN}$ & $0,01 \%$ & $0,00 \%$ & $0,00 \%$ & $0,03 \%$ & $0,16 \%$ & $0,20 \% *$ & $0,00 \%$ & $0,00 \%$ & $0,00 \%$ & $0,00 \%$ & $0,10 \%$ & $0,16 \%$ & $0,16 \%$ \\
\hline Mine Prod & $0,00 \%$ & $0,00 \%$ & $-0,11 \% *$ & $0,00 \%$ & $-0,03 \%$ & $0,00 \%$ & $-0,02 \%$ & $0,00 \%$ & $\mathrm{NaN}$ & $-0,15 \%$ ** & $0,00 \%$ & $-0,10 \%$ & $-0,01 \%$ & $0,00 \%$ & $0,00 \%$ & $-0,08 \%$ & $-0,18 \% *$ & $-0,07 \%$ & $0,00 \%$ & $-0,01 \%$ & $-0,01 \%$ \\
\hline AppConsum & $0,00 \%$ & $0,00 \%$ & $0,00 \%$ & $0,00 \%$ & $-0,04 \%$ & $0,00 \%$ & $0,00 \%$ & $0,00 \%$ & $-0,02 \%$ & $\mathrm{NaN}$ & $0,01 \%$ & $-0,09 \% *$ & $0,00 \%$ & $0,08 \%$ & $-0,01 \%$ & $0,00 \%$ & $-0,18 \% *$ & $-0,04 \%$ & $0,01 \%$ & $0,00 \%$ & $0,00 \%$ \\
\hline 2Prod & $-0,15 \%$ & $-0,06 \%$ & $-0,09 \%$ & $0,00 \%$ & $0,00 \%$ & $-0,15 \%$ & $-0,10 \%$ & $-0,04 \%$ & $-0,06 \%$ & $-0,12 \%$ & $\mathrm{NaN}$ & $0,19 \% *$ & $-0,05 \%$ & $0,00 \%$ & $-0,18 \% *$ & $0,00 \%$ & $-0,21 \% *$ & $-0,04 \%$ & $-0,05 \%$ & $-0,05 \%$ & $-0,05 \%$ \\
\hline Stocks & $0,00 \%$ & $0,00 \%$ & $-0,13 \% *$ & $-0,07 \%$ & $-0,08 \%$ & $0,00 \%$ & $0,00 \%$ & $-0,06 \%$ & $-0,15 \% *$ & $-0,09 \%$ & $-0,15 \% * *$ & $\mathrm{NaN}$ & $0,00 \%$ & $0,00 \%$ & $0,00 \%$ & $-0,12 \%$ & $-0,13 \%$ & $0,00 \%$ & $0,00 \%$ & $0,00 \%$ & $0,00 \%$ \\
\hline $\begin{array}{l}\text { Commodity } \\
\text { Index }\end{array}$ & $-0,10 \%$ & $-0,01 \%$ & $-0,05 \%$ & $0,00 \%$ & $0,00 \%$ & $-0,05 \%$ & $-0,07 \%$ & $-0,25 \%$ & $-0,05 \%$ & $0,00 \%$ & $0,00 \%$ & $0,00 \%$ & $\mathrm{NaN}$ & $0,00 \%$ & $0,00 \%$ & $0,07 \%$ & $0,00 \%$ & $0,04 \%$ & $0,00 \%$ & $0,00 \%$ & $0,00 \%$ \\
\hline Treasury Rate & $-0,26 \% * *$ & $-0,26 \% * *$ & $-0,25 \% * *$ & $-0,27 \% * *$ & $-0,21 \% *$ & $-0,13 \%$ & $-0,29 \%$ ** & $-0,34 \%$ ** & $-0,32 \% * *$ & $-0,31 \% * *$ & $-0,31 \% * * *$ & $-0,15 \%$ & $-0,41 \% * *$ & $\mathrm{NaN}$ & $-0,21 \%$ & $0,00 \%$ & $0,00 \%$ & $0,00 \%$ & $0,00 \%$ & $0,00 \%$ & $0,00 \%$ \\
\hline Exchange Rate & $0,00 \%$ & $0,00 \%$ & $0,00 \%$ & $0,00 \%$ & $0,00 \%$ & $0,00 \%$ & $0,00 \%$ & $0,00 \%$ & $0,00 \%$ & $0,01 \%$ & $0,19 \% *$ & $0,00 \%$ & $0,07 \%$ & $0,22 \%$ & $\mathrm{NaN}$ & $0,00 \%$ & $0,00 \%$ & $0,00 \%$ & $0,00 \%$ & $0,00 \%$ & $0,00 \%$ \\
\hline World GDP & $-0,18 \%$ & $-0,19 \%$ & $-0,20 \% *$ & $-0,04 \%$ & $-0,18 \%$ & $-0,24 \%$ & $-0,22 \% *$ & $-0,08 \%$ & $-0,23 \% *$ & $-0,13 \%$ & $-0,19 \%$ & $-0,06 \%$ & $-0,41 \% *$ & $-0,39 \% *$ & $-0,39 \% *$ & $\mathrm{NaN}$ & $0,00 \%$ & $0,00 \%$ & $0,00 \%$ & $0,00 \%$ & $0,00 \%$ \\
\hline $\begin{array}{l}\text { World Industrial } \\
\text { Production }\end{array}$ & $0,00 \%$ & $0,00 \%$ & $0,00 \%$ & $0,00 \%$ & $0,00 \%$ & $0,00 \%$ & $0,00 \%$ & $0,00 \%$ & $0,00 \%$ & $0,03 \%$ & $0,00 \%$ & $0,00 \%$ & $0,00 \%$ & $0,00 \%$ & $0,00 \%$ & $0,00 \%$ & $\mathrm{NaN}$ & $0,00 \%$ & $0,00 \%$ & $0,00 \%$ & $0,00 \%$ \\
\hline World Inflation & $0,00 \%$ & $-0,11 \%$ & $-0,07 \%$ & $0,00 \%$ & $0,00 \%$ & $-0,10 \%$ & $-0,03 \%$ & $-0,09 \%$ & $-0,17 \%$ & $-0,09 \%$ & $-0,13 \%$ & $0,00 \%$ & $-0,17 \%$ & $-0,04 \%$ & $-0,04 \%$ & $-0,04 \%$ & $-0,04 \%$ & $\mathrm{NaN}$ & $0,00 \%$ & $0,00 \%$ & $0,00 \%$ \\
\hline $\begin{array}{l}\text { Global Market } \\
\text { Factors }\end{array}$ & $-0,05 \%$ & $0,00 \%$ & $-0,10 \%$ & $0,00 \%$ & $0,00 \%$ & $0,00 \%$ & $-0,07 \%$ & $-0,18 \%$ & $-0,04 \%$ & $-0,02 \%$ & $0,00 \%$ & $0,00 \%$ & $-0,03 \%$ & $0,00 \%$ & $0,00 \%$ & $0,00 \%$ & $0,00 \%$ & $0,00 \%$ & $\mathrm{NaN}$ & $0,00 \%$ & $0,00 \%$ \\
\hline LMEX Index & $-0,10 \%$ & $-0,01 \%$ & $-0,05 \%$ & $0,00 \%$ & $0,00 \%$ & $-0,05 \%$ & $-0,07 \%$ & $-0,25 \%$ & $-0,05 \%$ & $0,00 \%$ & $0,00 \%$ & $0,00 \%$ & $0,00 \%$ & $0,00 \%$ & $0,00 \%$ & $0,00 \%$ & $0,00 \%$ & $0,00 \%$ & $0,00 \%$ & $\mathrm{NaN}$ & $0,00 \%$ \\
\hline GSCI All Metals & $-0,10 \%$ & $-0,01 \%$ & $-0,05 \%$ & $0,00 \%$ & $0,00 \%$ & $-0,06 \%$ & $-0,07 \%$ & $-0,25 \%$ & $-0,05 \%$ & $0,00 \%$ & $0,00 \%$ & $0,00 \%$ & $0,00 \%$ & $0,00 \%$ & $0,00 \%$ & $0,00 \%$ & $0,00 \%$ & $0,00 \%$ & $0,00 \%$ & $0,00 \%$ & $\mathrm{NaN}$ \\
\hline
\end{tabular}

Note: This table displays the results of two-way sorted metal portfolios. The respective characteristics are shown in the first column and first row. The respective value for each pair denotes the $\mathrm{J}$ statistic for the monotonic relation, which is the joint event of a characteristic's $C_{1}$ predictability given a second characteristic $C_{2}$, according to formula (4). Levels of statistical significance according to the monotonic relation (MR) Test are indicated by $*(10 \%), * *(5 \%)$, and *** $(1 \%)$. The returns of all portfolios are in excess of the one-month U.S. Treasury bill rate. 
Table 9: Median return of two-sorted metal portfolios based on transformations

\begin{tabular}{|c|c|c|c|c|c|}
\hline & & Absolute Value & Z-transformation & Log-Growth & $\begin{array}{c}\text { Rratio to total } \\
\text { production }\end{array}$ \\
\hline \multirow{6}{*}{ 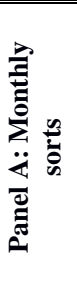 } & Value5 & $0,34 \% *$ & $0,34 \%$ * & $0,34 \% *$ & $0,34 \% *$ \\
\hline & Value4 & $0,09 \%$ & $0,13 \%$ & $0,09 \%$ & $0,14 \%$ \\
\hline & Value6 & $0,55 \% * * *$ & $0,56 \% * *$ & $0,54 \% * *$ & $0,53 \% * *$ \\
\hline & Momentum (2-6) & $0,29 \% * *$ & $0,30 \% * *$ & $0,30 \% *$ & $0,30 \% * *$ \\
\hline & Momentum (2-12) & $0,08 \%$ & $0,06 \%$ & $0,01 \%$ & $0,00 \%$ \\
\hline & Momentum (7-12) & $0,00 \%$ & $0,01 \%$ & $0,01 \%$ & $0,00 \%$ \\
\hline \multirow{6}{*}{ 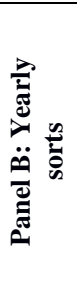 } & HHI Country & $0,09 \%$ & $0,00 \%$ & $-0,21 \% *$ & $0,06 \%$ \\
\hline & Reserves & $0,01 \%$ & $-0,18 \%$ & $0,00 \%$ & $0,00 \%$ \\
\hline & Mine Prod & $-0,01 \%$ & $-0,32 \% * *$ & $0,09 \%$ & $0,00 \%$ \\
\hline & AppConsum & $0,00 \%$ & $-0,01 \%$ & $0,27 \% * *$ & $0,00 \%$ \\
\hline & 2Prod & $-0,05 \%$ & $0,00 \%$ & $0,19 \% *$ & $0,00 \%$ \\
\hline & Stocks & $0,00 \%$ & $0,16 \% *$ & $-0,04 \%$ & $0,28 \% *$ \\
\hline \multirow{9}{*}{ 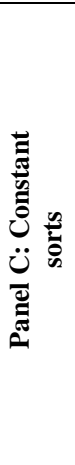 } & Commodity Index & $0,00 \%$ & $0,00 \%$ & $0,00 \%$ & $0,00 \%$ \\
\hline & Treasury Rate & $-0,25 \% * *$ & $-0,21 \%$ & $-0,21 \% *$ & $-0,26 \% *$ \\
\hline & Exchange Rate & $0,00 \%$ & $0,00 \%$ & $0,00 \%$ & $0,00 \%$ \\
\hline & World GDP & $-0,19 \%$ & $-0,19 \%$ & $-0,18 \%$ & $-0,24 \% *$ \\
\hline & $\begin{array}{l}\text { World Industrial } \\
\text { Production }\end{array}$ & $0,00 \%$ & $0,00 \%$ & $0,00 \%$ & $0,00 \%$ \\
\hline & World Inflation & $-0,04 \%$ & $-0,04 \%$ & $-0,04 \%$ & $-0,04 \%$ \\
\hline & $\begin{array}{l}\text { Global Market } \\
\text { Factor }\end{array}$ & $0,00 \%$ & $0,00 \%$ & $0,00 \%$ & $0,00 \%$ \\
\hline & LMEX Index & $0,00 \%$ & $0,00 \%$ & $0,00 \%$ & $0,00 \%$ \\
\hline & GSCI All Metals & $0,00 \%$ & $0,00 \%$ & $0,00 \%$ & $0,00 \%$ \\
\hline
\end{tabular}

Note: This table displays the median return of each characteristic's combination of the two-way sorted metal portfolios for each transformation. The characteristics are shown in the second column and the specific transformation in the first row. The respective median for each characteristic, furthermore, is indicated by its median level of statistical significance according to the monotonic relation (MR) Test by * (10\%), $* *(5 \%)$, and *** $(1 \%)$. The returns of all portfolios are in excess of the one-month U.S. Treasury bill rate.

\section{Robustness tests}

To validate the robustness of our results and to identify potential additional factors for portfolio building, we apply two classifications to our metals (see also Table 1): Exchange-traded or non-exchange-traded metals and precious or non-precious metals, respectively. Table 10 and Table 11 show portfolio sorts using both these classifications that are significant in the univariate analysis above.

The results are - at least at first view - surprising: exchange-traded metals (see Table 10) lose almost all significance for value and momentum, while these factors are highly significant in the univariate analysis using all metals. Mine production as well is no longer a significant sorting criterion for exchange-traded metals nor the treasury rate. In contrast, for non-exchange-traded metals, all these variables retain their significance. However, as these variables are neither new nor especially complicated, it is plausible that for highly traded metals they or their expected future values are already part of the current price, while market imperfections for non-exchangetraded metals prevent these variables from being fully included into the current price. In addition, precious metals 
make up a large part of exchange-traded metals, which makes them susceptible to the same effects as described for precious metals themselves, shown below.

The classification of "precious" vs. "non-precious" yields similar results (see Table 11): almost all significance is lost when only looking at precious metals, which in most cases are also exchange-traded. In contrast, all financial and fundamental metal-specific variables retain their significances for non-precious metals. However, the momentum (2-6) is even more significant for precious metals than for non-precious metals. This could point to especially strong irrational exuberance in the case of precious metals. In addition, the treasury rate loses all its significance for both precious and non-precious metals, indicating that this indicator has no robust influence on the expected returns. Generally, as precious metals show no value effect, it stands to reason that they exhibit much less cyclicity, e.g. due to the stabilizing effect of the jewelry trade and stores in general. In addition to these robustness tests, we also calculate the univariate results using U.S. variables like U.S. GDP or U.S. inflation, which perform generally commensurate with the respective global values.

Overall, this univariate robustness test shows that most of our results from the univariate analysis are predominantly robust, while some classes of metals (precious and exchange-traded) seem to be less suitable for our method, presumably because our basic method of portfolio sorts is well-known among investors and thus probably already included in the price.

Table 10: Characteristic-sorted portfolios with exchange-traded and non-exchange-traded metals

\begin{tabular}{|c|c|c|c|c|c|c|c|c|c|c|c|}
\hline \multirow{3}{*}{$\begin{array}{l}\text { Sorting } \\
\text { characteristic }\end{array}$} & & \multicolumn{5}{|c|}{ Exchange-traded metals } & \multicolumn{5}{|c|}{ Non-exchange-traded metals } \\
\hline & & $\mathrm{P}_{1}$ & $\mathrm{P}_{2}$ & $\mathrm{P}_{3}$ & $\mathrm{P}_{3}-\mathrm{P}_{1}$ & Factor & $\mathrm{P}_{1}$ & $\mathrm{P}_{2}$ & $\mathrm{P}_{3}$ & $\mathrm{P}_{3}-\mathrm{P}_{1}$ & Factor \\
\hline & \multicolumn{11}{|c|}{ Panel A: Monthly sorts } \\
\hline \multirow{2}{*}{$\begin{array}{c}\text { Value } \\
\text { (5 years })\end{array}$} & Mean Return & $-0,09 \%$ & $0,10 \%$ & $0,14 \%$ & $0,23 \%$ & $0,27 \%$ & $-0,69 \% * *$ & $0,47 \% * *$ & $0,09 \%$ & $0,78 \% * *$ & $0,76 \% * *$ \\
\hline & Avg. Com. & 4,00 & 4,00 & 4,00 & 8,00 & 12,00 & 5,58 & 5,69 & 5,58 & 11,16 & 16,85 \\
\hline \multirow{2}{*}{$\begin{array}{c}\text { Value } \\
\text { (6 years) }\end{array}$} & Mean Return & $-0,32 \%$ & $0,34 \%$ & $0,25 \%$ & $0,57 \% *$ & $0,60 \% *$ & $-0,57 \% * *$ & $0,17 \%$ & $0,35 \% *$ & $0,92 \% * * *$ & $0,96 \% * * *$ \\
\hline & Avg. Com. & 3,83 & 3,83 & 3,83 & 7,83 & 11,50 & 5,33 & 5,44 & 5,33 & 10,91 & 16,10 \\
\hline \multirow{3}{*}{$\begin{array}{c}\text { Momentum } \\
(2-6)\end{array}$} & Mean Return & $-0,07 \%$ & $0,01 \%$ & $0,20 \%$ & $0,27 \%$ & $0,16 \%$ & $-0,77 \% * * *$ & $-0,11 \%$ & $0,63 \% * *$ & $1,40 \% * * *$ & $1,28 \% * * *$ \\
\hline & Avg. Com. & 4,00 & 4,00 & 4,00 & 7,83 & 12,00 & 5,79 & 5,69 & 5,79 & 10,91 & 17,26 \\
\hline & \multicolumn{11}{|c|}{$\begin{array}{c}\text { Panel B: Yearly sorts } \\
\end{array}$} \\
\hline \multirow{3}{*}{$\begin{array}{c}\text { MineProd (z- } \\
\text { transform.) }\end{array}$} & Mean Return & $0,22 \%$ & $0,28 \%$ & $-0,23 \%$ & $-0,45 \%$ & $-0,41 \%$ & $0,23 \%$ & $-0,00 \%$ & $-0,42 \%$ & $-0,64 \% * *$ & $-0,63 \% *$ \\
\hline & Avg. Com. & 4,00 & 4,00 & 4,00 & 8,00 & 12,00 & 5,52 & 5,30 & 5,52 & 10,43 & 16,35 \\
\hline & \multicolumn{11}{|c|}{ Panel C: Constant sorts } \\
\hline \multirow{2}{*}{$\begin{array}{c}\text { Beta } \\
\text { (Treasury } \\
\text { Rate) }\end{array}$} & Mean Return & $-0,05 \%$ & $0,09 \%$ & $-0,20 \%$ & $-0,15 \%$ & $-0,14 \%$ & $0,00 \%$ & $-0,17 \%$ & $-0,20 \%$ & $-0,20 \%$ & $-0,94 \% *$ \\
\hline & Avg. Com. & 3,00 & 2,00 & 3,00 & 6,00 & 8,00 & 4,00 & 4,00 & 4,00 & 8,00 & 12,00 \\
\hline
\end{tabular}

Note: This table displays the results of metal portfolios formed monthly (Panel A), yearly (Panel B), and once (Panel C) according to a particular characteristic. These portfolios comprise either solely exchange-traded or solely non-exchange-traded metals. The respective characteristic is shown in the first column of the table. P1, P2, and P3 contain the metals whose values of the respective characteristic are below the one-third, between the one-third and two-third, and above the two-third percentile, respectively, of the characteristic's sample distribution at the time of the portfolio formation. The first line associated with each characteristic shows the means of the monthly returns (in \%) and the second line denotes the number of metals contained in the respective portfolio on average (in brackets). Levels of statistical significance according to the Student's t-distribution are indicated by * $(10 \%)$, ** $(5 \%)$, and *** $(1 \%)$. The returns of P1, P2, and P3 are in excess of the one-month U.S. Treasury bill rate. With regard to yearly sorts, the table only displays results for those characteristics that produce portfolios whose mean monthly return is significantly different from zero. 
Table 11: Characteristic-sorted portfolios with precious and non-precious metals

\begin{tabular}{|c|c|c|c|c|c|c|c|c|c|c|c|}
\hline & & & & Precious m & tals & & & & Non-prec & ous metals & \\
\hline Sorting & & $\mathrm{P}_{1}$ & $\mathrm{P}_{2}$ & $\mathrm{P}_{3}$ & $\mathrm{P}_{3}-\mathrm{P}_{1}$ & Factor & $\mathrm{P}_{1}$ & $\mathrm{P}_{2}$ & $\mathrm{P}_{3}$ & $\mathrm{P}_{3}-\mathrm{P}_{1}$ & Factor \\
\hline characteristic & & & & & Panel & A: Month & ly sorts & & & & \\
\hline Value & Mean Return & $0,20 \%$ & $0,25 \%$ & $-0,05 \%$ & $-0,25 \%$ & $-0,36 \%$ & $-0,52 \% * *$ & $0,22 \%$ & $0,16 \%$ & "0,68\%*** & $0,85 \% * * *$ \\
\hline (5 years) & Avg. Com. & 2,00 & 1,35 & 2,00 & 4,00 & 5,35 & 7,92 & 7,67 & 7,92 & 15,83 & 23,50 \\
\hline Value & Mean Return & $0,03 \%$ & $0,36 \%$ & $0,36 \%$ & $0,34 \%$ & $0,17 \%$ & $-0,65 \% * *$ & $0,15 \%$ & $0,45 \% * *$ & $1,10 \% * * *$ & $1,05 \% * * *$ \\
\hline (6 years) & Avg. Com. & 1,92 & 1,27 & 1,92 & 3,92 & 5,10 & 7,58 & 7,33 & 7,58 & 15,50 & 22,49 \\
\hline Momentum & Mean Return & $-0,67 \% *$ & $0,15 \%$ & $0,89 \% * * *$ & $1,56 \% * * *$ & $1,42 \% * * *$ & $-0,39 \% *$ & $-0,08 \%$ & $0,30 \%$ & $0,69 \% * *$ & $0,56 \% * *$ \\
\hline$(2-6)$ & Avg. Com. & 2,00 & 1,56 & 2,00 & 3,92 & 5,56 & 7,92 & 7,87 & 7,92 & 15,50 & 23,70 \\
\hline & & & & & Panel & B: Month & ly sorts & & & & \\
\hline MineProd (z- & Mean Return & $0,62 \%$ & $0,35 \%$ & $-0,13 \%$ & $-0,75 \%$ & $-0,63 \%$ & $0,08 \%$ & $-0,06 \%$ & $-0,11 \%$ & $-0,20 \%$ & $-0,58 \% * *$ \\
\hline transform.) & Avg. Com. & 2,00 & 1,61 & 2,00 & 4,00 & 5,61 & 7,83 & 7,09 & 7,83 & 14,83 & 22,74 \\
\hline & & & & & Panel & : Consta & nt sorts & & & & \\
\hline Beta (Treasury & Mean Return & $0,34 \%$ & $-0,04 \%$ & $0,11 \%$ & $-0,23 \%$ & $-0,15 \%$ & $-0,08 \%$ & $-0,06 \%$ & $-0,22 \%$ & $-0,14 \%$ & $-0,29 \%$ \\
\hline Rate) & Avg. Com. & 1,00 & 2,00 & 1,00 & 2,00 & 4,00 & 5,00 & 6,00 & 5,00 & 10,00 & 16,00 \\
\hline
\end{tabular}

Note: This table displays the results of metal portfolios formed monthly (Panel A) and once (Panel B) according to a particular characteristic. These portfolios comprise either only precious or only non-precious metals. The respective characteristic is shown in the first column of the table. P1, P2, and P3 contain the metals whose values of the respective characteristic are below the one-third, between the one-third and twothird, and above the two-third percentile, respectively, of the characteristic's sample distribution at the time of the portfolio formation. (P3P1) represents a strategy that buys P3 and sells P1. "Factor" denotes a rank-weighted portfolio that follows Asness et al. (2013) in its construction. The first line associated with each characteristic shows the means of the monthly returns (in \%) and the second line denotes the number of metals contained in the respective portfolio on average (in brackets). Levels of statistical significance according to the Student's tdistribution are indicated by $*(10 \%)$, ** (5\%), and *** (1\%). The returns of P1, P2, and P3 are in excess of the one-month U.S. Treasury bill rate. With regard to yearly sorts, the table only displays results for those characteristics that produce portfolios whose mean monthly return is significantly different from zero.

\section{Discussion}

\subsection{Financial variables}

Most clearly, our results show considerable predictive power for value and momentum. This supports the finding of mean reverting or cycling commodity prices in literature (Pindyck 1978; Cashin et al. 2002; Asness et al. 2013), possibly caused by cycles in production capacity due to lags in adaption to current equilibrium. In addition, our results are similar to those seen in other asset classes (see Asness et al. 2013, among many others).

The varying performance of value depending on the time frame particularly points to metal price cycles with a length of 5 or more years. Therefore, our analysis provides additional statistical evidence on the properties of metal price cycles, which is still an important yet sparsely researched topic (Cashin et al. 2002). The same applies to momentum: in reference to its standard time frame, momentum is significant when measured over the past 2 to 6 months, but a little less robust than value. From a resource point of view, this can be understood by interpreting momentum as being caused by short-run imbalances in supply and demand, which can be smoothed by adaptions in production volume from current capacity. A period of 2-6 months seems to be plausible for increases/decreases in volume and replenishment/drawdowns from current stocks. Generally, this finding of significant impact for momentum is consistent with recent literature (Erb and Harvey 2006; Fuertes and Miffre 2010; Asness et al. 2013). 
In addition, Szymanowska et al. (2014) report a momentum effect present in spot returns, which is consistent with our results on price returns.

From a financial point of view, the interpretation of our results depends on the degree of market efficiency. Market efficiency is, however, not per se testable, due to the joint hypothesis problem pointed out by Fama $(1970 ; 1991)$. Even Fama admits in a recent interview, "of all the potential embarrassments to market efficiency, momentum is the primary one" (Fama and Litterman 2012, p. 18). Therefore, our results for value and momentum could point to incorrect valuation of metals, as this information is not yet fully included in the current price, particularly in the case of non-exchange-traded metals. Similarly, momentum may suggest some kind of herding behavior in markets, also known as irrational exuberance (Shiller 2000). One may be tempted to explain such potential irrational exuberance by financialization of commodity markets due to increased investor activity (Domanski and Heath 2007). This is somewhat supported by our result that the fundamental factor of world mine production performs better for non-exchange-trade metals.

\subsection{Fundamental variables}

Our results on fundamental variables do not give as clear a picture as for the financial variables. When including the multivariate analysis, every fundamental metal-specific variable shows several significant results for at least one transformation. Altogether, the multivariate analysis provides a more detailed picture and yields several new results, indicating that the single sorts provide a valuable and robust result, that can be extended to the multiple analysis, which seems to provide more results than the sum of its parts, i.e.: the single sorts. These results are in particular relevant, as Fama and MacBeth type regressions would be mostly non-significant due to the low number of observations in this data set using cross-sections and portfolios.

Regarding our transformations of fundamental metal-specific variables, it is plausible that they are successful in capturing the intuitively and theoretically assumed relationships between returns and fundamentals. For instance, recent financial as well as economic publications (e.g. Bentzen 2007, Gallo et al. 2010 and Morana 2013) point to an important role of fundamental metal-specific factors like production, stocks, demand, or recycling for the price of commodities. In particular, according to literature, mine production is very relevant to the formation of (spot) prices, as shown for different commodities, by among others Ahumada and Cornejo (2015), Chai et al. (2011), and Morana (2013). Additional publications show that commodity futures are led by commodity-specific (Stepanek et al. 2013) as well as macroeconomic data (Backus et al. 2011), which may - to some degree - also apply to spot prices. Therefore, our comprehensive study concurs with many specific prior results. While our method is different 
and cannot fully account for multivariate dependencies, our results extend (but do not substitute) the results of classical VAR analyses.

However, the weak significances in at least some cases and the - in part - counterintuitive direction of influence impede a definite interpretation. Nevertheless, our results indicate both the importance of fundamental metalspecific factors, respectively, and the relevance of individually adapted transformations for each metal-specific fundamental variable. In contrast, macroeconomic variables - at least in our analysis - only seem to be relevant in some particular cases.

These limitations of our results can be due to a number of reasons: From a resource point of view, we can interpret the missing or weak significances with respect to the ongoing endogeneity debate present in literature on VAR models. For example, commodity prices lead consumption, due to the fact that higher commodity prices cause a reduction in consumption (see e.g. Barsky and Kilian 2004 or Zaremba 2014) and not vice versa. The same may also be true for monetary indicators, like interest rates. In this case, higher commodity prices force central banks to tighten their monetary policy and raise the interest rates (see e.g. Lastrapes and Selgin 2001).

From a financial point view, a possible explanation could be that new information from these factors is already incorporated in metal prices and is hence unrelated to subsequent returns, which in turn may be explained by Kilian and Vega's (2011) event study. They show that the publication of macroeconomic factors does not lead to significant reactions in oil prices. Hence, this effect could also hold for metal specific data, because market participants obtain the information well in advance (e.g. from leakages prior to publication, late publication, or insider knowledge), which in turn is already included in the price. Lastly, the poor performance of macroeconomic variables may well be caused by limitations inherent in our method. As these variables are not metal-specific (in contrast to financial and fundamental metal-specific variables yielding different time series values for every metal), we have only one beta value for each macroeconomic variable and thus only one constant portfolio for the whole time frame. Therefore, it is not completely surprising that one value is less useful for expected returns than a complete time series.

\section{Conclusion}

Strongly fluctuating metal prices alongside the increasing presence of financial participants in metal markets in the past decade has refueled the debate over the driving forces behind metal prices: are they fundamental or financial? To answer this important question, we applyed and extended a method very commonly found in finance literature to examine which factors describe the expected or average monthly returns of metals. We combined this 
method with both financial and fundamental variables as well as transformations aimed at a fundamental explanation of metal prices.

In particular, we sorted metals into portfolios according to one or two certain characteristics and examined whether the average returns of these characteristic-sorted portfolios differ significantly from each other. By conducting such a large cross-sectional empirical examination, we tested a comprehensive set of fundamental and financial characteristics for their explanatory power on subsequent returns, in a unique sample of 30 metals over a sample period of 24 years, ranging from January, 1990 to December, 2013.

Overall, we find that value (5 or 6 years) and momentum (2-6 months) can significantly predict returns of a broad range of metals, thereby extending the current literature of mostly index-listed commodity markets (e.g. Asness et al. 2013; Szymanowska et al., 2014). In addition, fundamental metal-specific variables like production, stocks, consumption, secondary production, country concentration or reserves can predict expected returns in some cases, when taking into account the economically interpretable transformations and when using multivariate two-way sorts. However, the direction of influence is often surprising and the results are by far not as significant and clear as in the case of value and momentum. Fundamental macroeconomic factors perform rather poorly, which is not surprising as they are not metal-specific and thus portfolios can only be built once, allowing no adaption to changing circumstances. In summary, albeit our results depend on the methodology (two-sorted portfolios) applied, from the perspective of expected returns, metals are predominantly assets, but portfolios also partially benefit from the additional information of fundamental metal-specific variables.

We hope that these robust results using mostly non-parametric methods (which is highly desirable regarding the mostly non-normally distributed data) will contribute to a better understanding of the driving forces behind metal prices and extend the results obtained by classical multivariate VAR regressions by using an alternative methodological approach. However, as future work, some extensions could provide additional insights. For instance, the application of our method to soft commodities would certainly be interesting, because other pertinent factors, such as weather and seasonal cyclicity, should also play an important role. 


\section{References}

Ahumada, H., Cornejo, M., 2015. Explaining commodity prices by a cointegrated time series-cross section model. Empirical Economics 48(2), 1667-1690.

Arango, L., Arias, F., Flórez, A., 2012. Determinants of commodity prices. Applied Economics 44(1), 135-145.

Asness, C.S., Moskowitz, T.J., Pedersen, L.H., 2013. 'Value and momentum everywhere'. Journal of Finance 68(3), 929-985.

Backus, D., M. Chernov, M., Martin I., 2011. Disasters implied by equity index options, Journal of Finance 66(6), 1967-2009.

Baffes, J., Savescu, C., 2014. Monetary conditions and metal prices. Applied Economics Letters 21(7), 447-452.

Barsky, R., Kilian, L., 2004. Oil and the macroeconomy since the 1970s. Journal of Economic Perspectives 18(4), 115-134.

Belke, A., Bordon, I., Hendricks, T., 2010. Global liquidity and commodity prices - a cointegrated VAR approach for OECD countries. Applied Financial Economics 20(3), 227-242.

Belke, A., Bordon, I., Hendricks, T., 2014. Monetary policy, global liquidity and commodity price dynamics. North American Journal of Economics and Finance 28(2), 1-16.

Bentzen, J., 2007. Does OPEC influence crude oil prices? Testing for co-movements and causality between regional crude oil prices. Applied Economics 39(11), 1375-1385.

Borensztein, E., Reinhart, C.M., 1994. The macroeconomic determinants of commodity prices. IMF Staff Papers, 41(2), 236-261.

Breeden, D. T., 1980. Consumption risk in futures markets. Journal of Finance, 35(2), 503-520.

Cashin, P., McDermott, C. J., Scott, A., 2002. Booms and slumps in world commodity prices. Journal of Development Economics 69(1), 277-296.

Chai, J., Guo, J.-E., Meng, L. Wang, S.-Y., 2011. Exploring the core factors and its dynamic effects on oil price: An application on path analysis and BVAR-TVP model. Energy Policy 39(12), 8022-8036.

Chen, S.-L., Jackson, J., Kim, H., Resiandini, P., 2016. What drives commodity prices? American Journal of Agricultural Economics 2016 forthcoming.

Cochrane, J. H., 2005. Asset pricing (Rev. ed.). N.J: Princeton University Press, Princeton.

Cochrane, J. H., 2011. Presidential address: discount rates. Journal of Finance 66(4), 1047-1108.

Coleman, L., 2012. Explaining crude oil prices using fundamental measures. Energy Policy 40(1), 318-324.

Domanski, D., Heath, A., 2007. Financial investors and commodity markets. BIS Quarterly Review, 3, 53-67.

Dusak, K., 1973. Futures trading and investor returns: An investigation of commodity market risk premiums. Journal of Political Economy 81(6), 1387-1406.

Erb, C. B., Harvey, C. R., 2006. The strategic and tactical value of commodity futures. Financial Analysts Journal, 62(2), 69-97. 
Fama, E. F., 1970. Efficient capital markets: a review of theory and empirical work. Journal of Finance 25(2), 383417.

Fama, E. F., 1991. Efficient capital markets: II. Journal of Finance 46(5), 1575-1617.

Fama, E. F., French, K. R., 1992. The cross-section of expected stock returns, Journal of Finance 47(2), 427-465.

Fama, E. F., French, K. R., 2012. Size, value, and momentum in international stock returns. Journal of Financial Economics 105(3), 457-472.

Fama, E. F., Litterman, R., 2012. An experienced view on markets and investing. Financial Analysts Journal 68(6), $15-19$.

Fama, E. F., MacBeth, J. D., 1973. Risk, return, and equilibrium: Empirical tests. Journal of Political Economy 81(3), 607-636.

Frankel J., 1986. Expectations and commodity price dynamics: The overshooting model, American Journal of Agricultural Economics 68(2), 344-348.

Frankel J., 2008. The effect of monetary policy on real commodity prices, Asset Prices and Monetary Policy, Campbell.

Fuertes, A., Miffre, J., Rallis, G., 2010. Tactical allocation in commodity futures markets: Combining momentum and term structure signals. Journal of Banking and Finance, 34(10), 2530-2548.

Gallo, A., Mason, P., Shapiro, S., Fabritius, M., 2010. What is behind the increase in oil prices? Analyzing oil consumption and supply relationship with oil price. Energy 35(10), 4126-4141.

Gleich, B., Achzet, B., Mayer, H., Rathgeber, A., 2013. An empirical approach to determine specific weights of driving factors for the price of commodities. Resources Policy 38(3), 350-362.

Hong, H., Yogo, M., 2012. What does futures market interest tell us about the macroeconomy and asset prices? Journal of Financial Economics 105(3), 473-90.

Jegadeesh, N., Titman, S., 1993. Returns to buying winners and selling losers: Implications for stock market efficiency, Journal of Finance 48(1), 65-91.

Kilian, L., 2009. Not all oil price shocks are alike: disentangling demand and supply shocks in the crude oil market. American Economic Review, 99(3), 1053-69.

Kilian, L., Vega, C., 2011. Do energy prices respond to U.S. macroeconomic news? A test of the hypothesis of predetermined energy prices. Review of Economics and Statistics 93(2), 660-671.

Klotz, P., Lin, T. C., Hsu, S.-H. 2014. Global commodity prices, economic activity and monetary policy. Resources Policy 42(1), 1-9.

Lastrapes, W., Selgin, G., 2001. An analysis of the statistical relationship between precious metals prices and monetary policy. Working Paper University of Georgia (http://people.terry.uga.edu/last/papers/gold/update.pdf).

Lutzenberger, F. T., 2014. The predictability of aggregate returns on commodity futures. Review of Financial Economics 23(3), 120-30. 
Merion, A., Ortiz, A., 2005. Explaining the so-called “price premium” in oil markets. OPEC Review 29(2), 133152.

Merton, R., 1973. An intertemporal capital asset pricing model. Econometrica 41(5), 867-887.

Morana, C., 2013. Oil price dynamics, macro-finance interactions and the role of financial speculation. Journal of Banking and Finance, 37, 206-226.

Nick, S., Thoenes, S., 2014. What drives natural gas prices? - A structural VAR approach. Energy Economics, 45(3), 517-527.

Novy-Marx, R., 2012. Is momentum really momentum? Journal of Financial Economics 103(3), 429-453.

Patton, A. J., Timmermann A., 2010. Monotonicity in asset returns: New tests with applications to the term structure, the CAPM, and portfolio sorts. Journal of Financial Economics 98(3) 605-625.

Pindyck, R., 1978. The optimal exploration and production of nonrenewable resources. Journal of Political Economy 86(5), 841-861.

Politis, D. N., Romano, J. P., 1994. The stationary bootstrap. Journal of the American Statistical Association 89(4), 1303-1313.

Poncela, P., Senra, E., Sierra, L., 2014. Common dynamics of nonenergy commodity prices and their relation to uncertainty. Applied Economics 46(30), 3724-3735.

Rangvid, J., 2006. Output and expected returns. Journal of Financial Economics 81(3), 595-624.

Sharpe, W. F., 1964. Capital asset prices: a theory of market equilibrium under conditions of risk. Journal of Finance 19, 425-442.

Shiller, Robert J., 2000. Irrational exuberance. Princeton University Press.

Stepanek, C., Walter M., Rathgeber, A., 2013. Is the convenience yield a good indicator for a commodities' supply risk? Resources Policy 38(3), 395-405.

Szymanowska, M., De Roon, F., Nijman, T., van den Goorbergh, R., 2014. An anatomy of commodity futures risk premia. Journal of Finance 69(1), 453-482.

Zaremba, A., 2014. Macroeconomic determinants of commodity returns in financialized markets. International Journal of Economics and Finance 6(5), 147-162. 